University of Wollongong

Research Online

Faculty of Engineering and Information

Faculty of Engineering and Information

Sciences - Papers: Part A

Sciences

$1-1-2014$

Evidence of solid-solution reaction upon lithium insertion into cryptomelane K0.25Mn204 material

Wei Kong Pang

University of Wollongong, wkpang@uow.edu.au

Vanessa Peterson

ANSTO, vep@ansto.gov.au

Neeraj Sharma

ANSTO

Chaofeng Zhang

University of Wollongong, czhang@uow.edu.au

Zaiping Guo

University of Wollongong, zguo@uow.edu.au

Follow this and additional works at: https://ro.uow.edu.au/eispapers

Part of the Engineering Commons, and the Science and Technology Studies Commons

Research Online is the open access institutional repository for the University of Wollongong. For further information contact the UOW Library: research-pubs@uow.edu.au 


\title{
Evidence of solid-solution reaction upon lithium insertion into cryptomelane K0.25Mn204 material
}

\begin{abstract}
Cryptomelane-type K0.25Mn204 material is prepared via a template-free, one-step hydrothermal method. Cryptomelane K0.25Mn2O4 adopts an I 4/m tetragonal structure with a distinct tunnel feature built from $\mathrm{MnO6}$ units. Its structural stability arises from the inherent stability of the MnO6 framework which hosts potassium ions, which in turn permits faster ionic diffusion, making the material attractive for application as a cathode in lithium-ion batteries. Despite this potential use, the phase transitions and structural evolution of cryptomelane during lithiation and delithiation remains unclear. The coexistence of Mn3+ and $\mathrm{Mn} 4+$ in the compound during lithiation and delithiation processes induce different levels of Jahn-Teller distortion, further complicating the lattice evolution. In this work, the lattice evolution of the cryptomelane $\mathrm{K} 0.25 \mathrm{Mn} 2 \mathrm{O} 4$ during its function as a cathode within a lithium-ion battery is measured in a customized coin-cell using in-situ synchrotron X-ray diffraction. We find that the lithiation-delithiation of cryptomelane cathode proceeds through a solid-solution reaction, associated with variations of the a and c lattice parameters and a reversible strain effect induced by Jahn-Teller distortion ofMn3+. The lattice parameter changes and the strain are quantified in this work, with the results demonstrating that cryptomelane is a relatively good candidate cathode material for lithium-ion battery use.
\end{abstract}

\section{Keywords}

solution, $25 \mathrm{mn} 2 \mathrm{o} 4$, reaction, material, upon, lithium, insertion, into, cryptomelane, $\mathrm{k0}$, evidence, solid

\section{Disciplines}

Engineering | Science and Technology Studies

\section{Publication Details}

Pang, W., Peterson, V. K., Sharma, N., Zhang, C. \& Guo, Z. (2014). Evidence of solid-solution reaction upon lithium insertion into cryptomelane K0.25Mn204 material. The Journal of Physical Chemistry Part C:

Nanomaterials and Interfaces, 118 (8), 3976-3983. 


\title{
Evidence of Solid-solution Reaction upon Lithium Insertion into Cryptomelane- $\mathrm{K}_{0.25} \mathrm{Mn}_{2} \mathrm{O}_{4}$ Material
}

\author{
Wei Kong Pang ${ }^{\dagger, t *}$, Vanessa K. Peterson ${ }^{\ddagger}$, Neeraj Sharma ${ }^{\S}$, Chaofeng Zhang ${ }^{\dagger}$, Zaiping Guo ${ }^{\dagger *} *$ \\ $\dagger$ School of Mechanical, Materials, and Mechatronic Engineering, Institute for Superconducting \\ \& Electronic Materials, Faculty of Engineering, University of Wollongong, NSW 2522, \\ Australia.
}

† The Bragg Institute, Australian Nuclear Science and Technology Organization, Locked Bag 2001, Kirrawee DC, NSW 2232, Australia.

$\S$ School of Chemistry, University of New South Wales, Sydney NSW 2052, Australia.

* To whom correspondence should be addressed.

Prof. Zaiping Guo

Email: zguo@uow.edu.au

Tel: +61242215225

Fax: +61242215731 
ABSTRACT: Cryptomelane-type $\mathrm{K}_{0.25} \mathrm{Mn}_{2} \mathrm{O}_{4}$ material is prepared via a template-free, one-step hydrothermal method. Cryptomelane $\mathrm{K}_{0.25} \mathrm{Mn}_{2} \mathrm{O}_{4}$ adopts an I 4/m tetragonal structure with a distinct tunnel feature built from $\mathrm{MnO}_{6}$ units. Its structural stability arises from the inherent stability of the $\mathrm{MnO}_{6}$ framework which hosts potassium ions, which in turn permits faster ionic diffusion, making the material attractive for application as a cathode in lithium-ion batteries. Despite this potential use, the phase transitions and structural evolution of cryptomelane during lithiation and delithiation remains unclear. The coexistence of $\mathrm{Mn}^{3+}$ and $\mathrm{Mn}^{4+}$ in the compound during lithiation and delithiation processes induce different levels of Jahn-Teller distortion, further complicating the lattice evolution. In this work, the lattice evolution of the cryptomelane $\mathrm{K}_{0.25} \mathrm{Mn}_{2} \mathrm{O}_{4}$ during its function as a cathode within a lithium-ion battery is measured in a customized coin-cell using in-situ synchrotron X-ray diffraction. We find that the lithiationdelithiation of cryptomelane cathode proceeds through a solid-solution reaction, associated with variations of the $a$ and $c$ lattice parameters and a reversible strain effect induced by Jahn-Teller distortion of $\mathrm{Mn}^{3+}$. The lattice parameter changes and the strain are quantified in this work, with the results demonstrating that cryptomelane is a relatively good candidate cathode material for lithium-ion battery use.

KEYWORDS: In-situ lattice evolution; lithium ion battery; cathode; Jahn-Teller effect; strain. 


\section{INTRODUCTION}

The search for cathode materials for lithium-ion batteries that are made from low cost components, are environmental friendly, and safe, alongside meeting performance requirements of high energy and power densities and cycling stability, is still a challenge. ${ }^{1,2}$ Manganese oxides are well-studied materials but are not very well-known for their properties as cathodes in lithiumion batteries. ${ }^{3,4}$ Nevertheless, for all types of $\mathrm{MnO}_{2}$ compounds, during lithiation Mn ions dynamically change oxidation states between $\mathrm{Mn}^{4+}$ and $\mathrm{Mn}^{3+}$, often resulting in mixed-valent $\mathrm{Mn}$ as determined through ex situ studies. ${ }^{5}$ Owing to the high-spin configuration of $\mathrm{Mn}^{3+}$ consisting of four unpaired electrons with parallel spin, the atomic arrangement in $\mathrm{MnO}_{2}$ compounds is distorted from ideal symmetrical packing by the cooperative Jahn-Teller effect as a result of the $\mathrm{Mn}^{3+}$. 5,6 The Jahn-Teller distortion of $\mathrm{Mn}^{3+}$ lead to an asymmetric deformation of $\mathrm{Mn}^{3+} \mathrm{O}_{6}$ octahedra during $\mathrm{MnO}_{2}$ lithiation-delithiation that can cause irreversible capacity fading during cycling. It has also been demonstrated that alkaline or alkaline-earth ions can be introduced and hosted in cathode materials, enhancing their electrochemical performance. ${ }^{7,8}$ This enhancement is probably due to structural stabilization during the lithium insertion/extraction process in combination with an increased interlayer spacing, acting to increase the ion diffusion-rate and accessible volume for lithium-ions in such materials. ${ }^{7-10}$ However, the interplay between the alkaline ions and lithium ion migration in the material remains unclear.

Cryptomelane-type $\mathrm{K}_{0.25} \mathrm{Mn}_{2} \mathrm{O}_{4}$ is a member of the manganese-oxide family, adopting an $\mathrm{I} 4 / \mathrm{m}$ tetragonal structure with the $\mathrm{MnO}_{6}$ framework featuring pore tunnels, similar to $\alpha-\mathrm{MnO}_{2}$. Cryptomelane-type materials have been prepared by different approaches, which can result in different morphology, particle size, and distributions. ${ }^{11-16}$ Although cryptomelane was originally developed and used as a molecular sieve in the field of heterogeneous catalysis, harnessing 
advantageously the tunnel structural feature, ${ }^{12,14,15}$ it is also a potential cathode material for lithium-ion battery technology because of its inherent structural stability induced by the $\mathrm{MnO}_{6}$ framework with hosted potassium ions, which in turn permits faster ionic diffusion. ${ }^{16}$ A crystal structure of cryptomelane is shown in Figure 1. We recently have investigated the electrochemical properties of $\mathrm{K}_{0.25} \mathrm{Mn}_{2} \mathrm{O}_{4}$ microclusters assembled from single-crystalline nanofibers and found this material can be used as a cathode in lithium rechargeable batteries. ${ }^{16} \mathrm{~A}$ mechanism to describe the reversible insertion/extraction of lithium in the $\mathrm{K}_{0.25} \mathrm{Mn}_{2} \mathrm{O}_{4}$ cathode during discharge/charge was also proposed based on X-ray photoemission spectroscopy (XPS) results. ${ }^{16}$

$\mathrm{K}_{0.25} \mathrm{Mn}_{2} \mathrm{O}_{4}+x \mathrm{Li}+x \mathrm{e}^{-} \rightarrow \mathrm{Li}_{x} \mathrm{~K}_{0.25} \mathrm{Mn}_{2} \mathrm{O}_{4}$

(First discharge process)

$\mathrm{Li}_{x} \mathrm{~K}_{0.25} \mathrm{Mn}_{2} \mathrm{O}_{4}-y \mathrm{Li}-m \mathrm{~K}-(y+m) \mathrm{e}^{-} \rightarrow \mathrm{Li}_{x-y} \mathrm{~K}_{0.25-m} \mathrm{Mn}_{2} \mathrm{O}_{4}$

(First charge process)

$$
\mathrm{Li}_{x-y} \mathrm{~K}_{0.25-m} \mathrm{Mn}_{2} \mathrm{O}_{4}+z \mathrm{Li}+z \mathrm{e}^{-} \rightarrow \mathrm{Li}_{x-y+z} \mathrm{~K}_{0.25-m} \mathrm{Mn}_{2} \mathrm{O}_{4}
$$

(Reversible electrochemical reaction)

When $x \mathrm{Li}^{+}$ions are intercalated into the $\mathrm{K}_{0.25} \mathrm{Mn}_{2} \mathrm{O}_{4}$ electrode during the first discharge (Eq. 1), $y \mathrm{Li}^{+}$ions, together with $m \mathrm{~K}^{+}$ions (Eq. 2), are de-intercalated from the cathode in the corresponding first charge process. Since $\mathrm{K}^{+}$is extracted from the electrode during first charge, this creates some vacant active sites in the electrode which are available for $z \mathrm{Li}^{+}$in the following discharge process (Eq. 3). This results in increasing capacity over the course of cycling. 

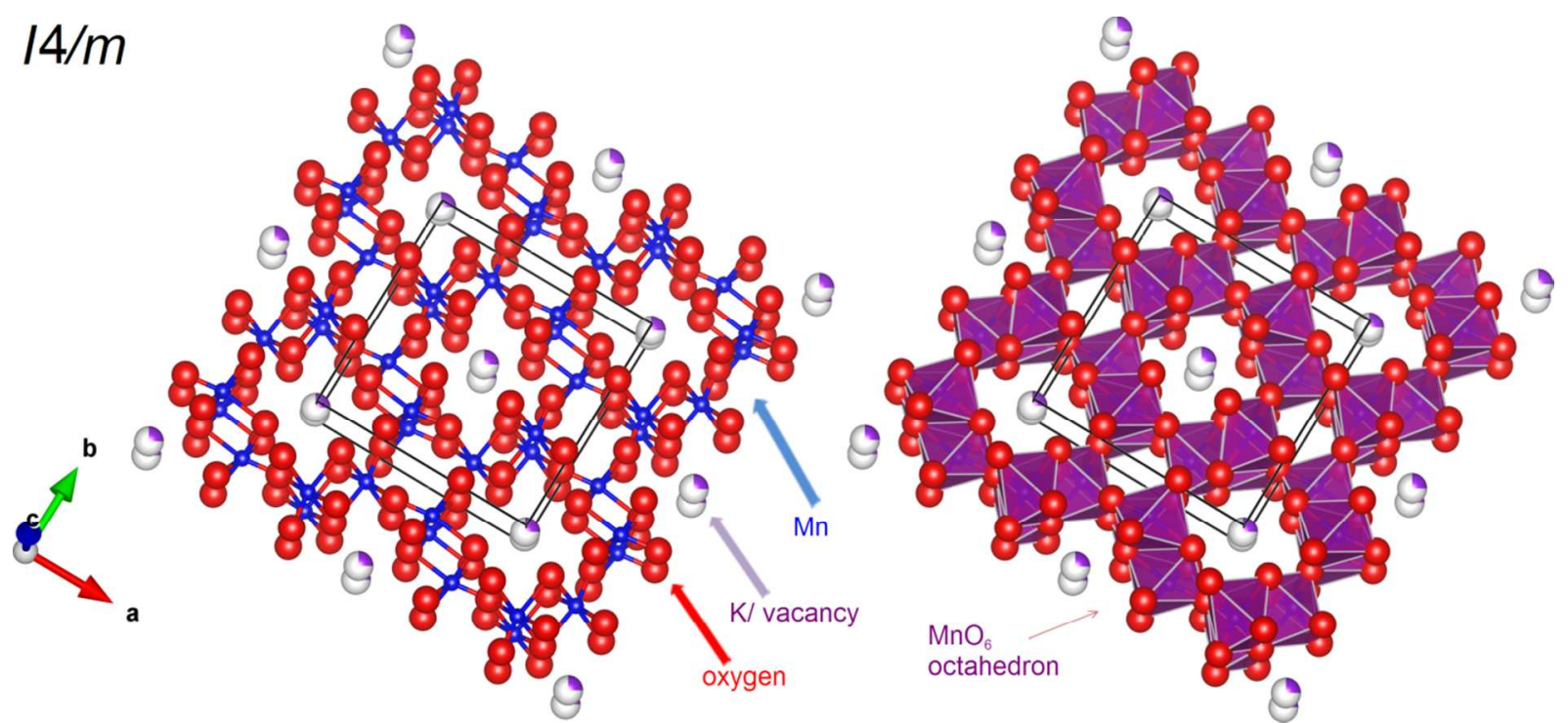

Figure 1. Crystal structure of cryptomelane $\mathrm{K}_{\mathrm{X}} \mathrm{Mn}_{2} \mathrm{O}_{4}$ showing tunnel structure along the (001) that allows fast diffusion via the $4 e$ site. The red and light-blue balls are oxygen and manganese ions, respectively. The balls with 3-quarter white and 1-quarter purple denote the potassium ions and vacancies at $4 e$ site that allows lithium ions diffusion.

As both $\mathrm{K}^{+}$and $\mathrm{Li}^{+}$can occupy the $4 e$ site in the crystal structure of $\mathrm{K}_{0.25} \mathrm{Mn}_{2} \mathrm{O}_{4}$, it is expected that the amount of $\mathrm{Mn}$ ions in the 3+ valence state will increase during lithiation and decrease during delithiation, to maintain charge neutrality. $\mathrm{Mn}^{3+}$ gives rise to Jahn-Teller distortion and consequently strain in the electrode. Assuming non-uniform strain as a result of Jahn-Teller distortion, i.e. non-uniform over the crystal, the strain can be quantified during a powder diffraction experiment through the observation of peak broadening. Stokes and Wilson suggested that the weighted average strain $<_{\varepsilon}>$ can be expressed as:

$$
\langle\varepsilon\rangle=\frac{B}{\tan \theta}
$$

where $\mathrm{B}$ is the integral breadth of the reflection and can be derived from the full-width at half maximum (FWHM) using standard peak-fitting. 


$$
B=\left(\frac{\pi}{4 \ln 2}\right)^{1 / 2} \times \mathrm{FWHM}
$$

In addition, Vegard's law is an approximate empirical relationship which leads to a linear relation between lattice parameter and the concentration of a "guest" element of the crystal structure. ${ }^{17}$ The expansion and contraction of the lattice parameters $a$ and $c$ can therefore be related to the lithium (and also potassium) concentration during cycling if the reaction mechanism taking place is a solid-solution and follows Vegard's law. Moreover, the volume of a tetragonal structure, such as cryptomelane, is the product of the square of lattice parameter $a$ (proportional to the tunnel size) and the lattice parameter $c$ (height of the rectangular prism). As shown in Figure 1, the rectangular prism has a significant smaller height, providing a short diffusion path to lithium ions diffusion along (001), and a Mn-O framework, supporting the structural stability against lattice deformation during lithiation and delithiation.

To the best of our knowledge, the phase transitions and structural evolution of cryptomelane during lithiation and delithiation still remain unclear. Although it can be assumed from the structure that lithium insertion and extraction follows a 1-dimensional pathway along the $c$ direction, some fundamental atomic level questions such as the expected anisotropic change in the lattice and $\mathrm{MnO}_{6}$ octahedra distortion as expected from the Jahn-Teller distortion common for $\mathrm{MnO}_{2}$ materials ${ }^{5,6}$ remain a mystery. Moreover, the contribution from the potassium ions in the lithium insertion/extraction mechanism during cycling may provide insight on how materials like cryptomelane and cathode compositions in general can be optimised through alkali-ion addition. In this work, the lattice evolution of the cryptomelane $\mathrm{K}_{0.25} \mathrm{Mn}_{2} \mathrm{O}_{4}$ and the strain induced by Jahn-Teller distortion of $\mathrm{Mn}^{3+}$ during its function as a cathode within a lithium-ion battery is quantified using in-situ synchrotron X-ray diffraction. 


\section{EXPERIMENTAL SECTION}

Manganese (II) acetate tetrahydrate $\left(\mathrm{Mn}\left(\mathrm{C}_{2} \mathrm{H}_{3} \mathrm{O}\right)_{2} \cdot 4 \mathrm{H}_{2} \mathrm{O}\right) \quad 99 \%$, oxone monopersulfate compound $\left(2 \mathrm{KHSO}_{5} \cdot \mathrm{KHSO}_{4} \cdot \mathrm{K}_{2} \mathrm{SO}_{4}\right)$, and potassium nitrate $\left(\mathrm{KNO}_{3}\right)$ all from Sigma-Aldrich Co. Ltd were used as starting materials for the cryptomelane synthesis and all reagents were used without any further purification. Nanofiber microclusters of cryptomelane-type manganese oxide $\left(\mathrm{K}_{0.25} \mathrm{Mn}_{2} \mathrm{O}_{4}\right)$ were prepared via a template-free, one-step hydrothermal method. ${ }^{15}$ Manganese (II) acetate tetrahydrate $(0.2 \mathrm{~g})$, potassium nitrate $(0.165 \mathrm{~g})$, and oxone monopersulfate $(1.5 \mathrm{~g})$ compound were dissolved and mixed in de-ionized water and the resultant mixture was transferred to an autoclave and kept in an oven at $80{ }^{\circ} \mathrm{C}$ for 20 hours. After the hydrothermal process, the product was washed with de-ionized water, centrifugally separated and dried at 60 ${ }^{\circ} \mathrm{C}$ in vacuum. The microstructure of the as-prepared sample was characterized by XRD (GBC MMA diffractometer) with CuK $\alpha$ radiation at a scanning rate of $2^{\circ} \mathrm{min}^{-1}$ in the $2 \theta$ range of 10$80^{\circ}$. The cryptomelane structure was refined against the XRD data using the structural model adopting $I$ 4/m symmetry ${ }^{18}$ using Rietica version 1.7.7. ${ }^{19}$ The as-prepared sample was also examined using field-emission SEM (JEOL JSM-7500FA) and TEM (JEOL 2011200 kV with a JEOL energy-dispersive X-ray spectroscopy detector (EDS) and a JEOL EDS software analysis system).

A customized CR2032 coin cell was designed and made were the working electrodes were prepared by mixing as-prepared $\mathrm{K}_{0.25} \mathrm{Mn}_{2} \mathrm{O}_{4}$ (75 wt.\%) with carbon black (15 wt.\%) and polyvinylidene difluoride (10 wt.\%, PVdF, Sigma-Aldrich) binder in anhydrous N-methyl-2pyrrolidinone (NMP, Sigma-Aldrich, 99.5\%) to form a homogeneous slurry. The slurry was uniformly pasted onto aluminum foil before being dried in a vacuum oven at $100{ }^{\circ} \mathrm{C}$ for over 12 hours, and finally pressed prior to the assembly of the coin cell. A CR2032 coin-type cell using 
the $\mathrm{K}_{0.25} \mathrm{Mn}_{2} \mathrm{O}_{4}$ working electrode, $\mathrm{Li}$ foil as the counter electrode, a microporous polypropylene film as the separator, and $1 \mathrm{M} \mathrm{LiPF}_{6}$ in a 1:1 (v/v) mixture of ethylene carbonate (EC) and diethyl carbonate (DEC) as the electrolyte, was assembled in an Ar-filled glove box $\left(\mathrm{H}_{2} \mathrm{O} \& \mathrm{O}_{2}\right.$ $<0.1 \mathrm{ppm}$, Mbraun). Holes for permitting synchrotron beam transmission were punched in the top and bottom casing of the coin-cell that were then sealed by kapton tape and wax to protect the contents of the cell from the air. The cell was galvanostatically charged and discharged over a voltage range of $1.5-4.2 \mathrm{~V}$ vs. $\mathrm{Li}$ at constant current of $0.5742 \mathrm{~mA}$ (equivalent to $0.1 \mathrm{C}$ ) during the data collection. SXRD experiments were conducted at the Powder Diffraction beamline at the Australian Synchrotron where data were collected every 150 seconds during battery cycling. Due to the breadth and subsequent overlap of the phase reflections as a result of the small particle size, the lattice response was extracted from a Rietveld calculated fit where the structure was not refined, avoiding unambiguity in the indexing due to constraint of the reflection intensities. To further justify this result, the lattice parameters calculated from the Rietveld method were reconciled with results from single-peak fitting analysis. Single-peak fitting was performed using the Large-Array Manipulation Program (LAMP) ${ }^{20}$ and sequential Rietveld refinement was undertaken using Fullprof with visualization in WinplotR. ${ }^{21,22}$ The refineable parameters included the background coefficients, peak shape parameters, zero-shift, oxygen positional parameters, and isotropic atomic displacement parameters for single-pattern refinements (at OCV, discharge states and charge state). The zero-shift, peak-shape parameters (except W), oxygen positional parameters, and isotropic atomic displacement parameters are fixed during a highly constrained sequential refinement. The figures of merit for the sequential refinement include the Bragg statistical reliability factor $\left(R_{B}\right)$, the weighted profile factor $\left(R_{w p}\right)$, 
the expected $\mathrm{R}$ parameter $\left(\mathrm{R}_{\mathrm{exp}}\right)$, and the goodness-of-fit $\left(\chi^{2}\right.$, defined as the square of the ratio of $\left.\mathrm{R}_{\mathrm{wp}} / \mathrm{R}_{\mathrm{exp}}\right)$, and are presented in Table $\mathrm{S} 1$.

\section{RESULTS AND DISCUSSION}

Rietveld analysis of the X-ray powder diffraction (XRD) pattern of the as-prepared $\mathrm{K}_{0.25} \mathrm{Mn}_{2} \mathrm{O}_{4}$ microclusters (Figure S1) indicate that tetragonal $(\mathrm{I} / \mathrm{m}) \mathrm{K}_{0.25} \mathrm{Mn}_{2} \mathrm{O}_{4}$ is exclusively observed. The crystallographic details of the phase are presented in Table 1. The broad peaks in the X-ray pattern suggest a small crystallite size. Gaussian fitting of the $\mathrm{K}_{0.25} \mathrm{Mn}_{2} \mathrm{O}_{4} 130$ reflection at $2 \theta=$ $28.69^{\circ}$ reveals the full-width at half-maximum (FWHM) to be $1.154(6)^{\circ}$, indicating a mean crystallite size of $\sim 70.5 \AA(7.05 \mathrm{~nm})$, calculated using the Scherrer equation. ${ }^{23}$ The particle size and morphology of the as-prepared sample were also investigated using scanning electron and transmission electron microscopy (SEM and TEM, respectively). The micrographs are shown in Figure 2 (a - d). Each particle is fiber-like, with individual particles forming a spherical microcluster as a secondary particle. The fiber-like particles have a diameter of about 6-8 nm which agrees well with the broad peaks observed in the XRD and the corresponding calculated mean crystallite size. Due to the nano particle size of the material, we believe synchrotron might be more superior in resolving the high background and broad peak shapes, than neutron-based techniques, although a successful case on similar material - $\mathrm{Li}\left(\mathrm{Co}_{0.16} \mathrm{Mn}_{1.84}\right) \mathrm{O}_{4}$ cathode using insitu neutron diffraction has been demonstrated. ${ }^{24}$

In situ synchrotron X-ray powder diffraction (SXRD) patterns from a customized coin-cell containing the cryptomelane cathode in a selected $2 \theta$ region are presented in Figure 3 . In addition to the cryptomelane phase, the reflections of the aluminum current collector (at $2 \theta \sim$ $20.5,23.7$, and $\left.33.8^{\circ}\right)$ and a broad feature from carbon $\left(2 \theta \sim 11.3^{\circ}\right)$ are also detected. We find no 
evidence for a two phase reaction of the cryptomelane during charging and discharging as supported by the lack of peak splitting or the emergence of new peaks, indicating that the cryptomelane undergoes a solid-solution transition accompanied by lattice changes. Sequential Rietveld refinements of the cryptomelane structure obtained from the XRD data using SXRD data where the strong Al reflections were excluded was performed. The Rietveld calculated profile fit for the first in situ SXRD dataset is shown in Figure 4. The lattice parameters were found to be $a=b=9.9806(5) \AA$ and $c=2.8785(2) \AA$ at an open-circuit voltage (OCV) of $2.76 \mathrm{~V}$ vs. Li. We note that the lattice parameters obtained for the cathode at this OCV are higher than those of the as-prepared powders. It is not unusual to see the different lattice parameters and from the SXRD results that the cryptomelane expand upon lithiation, we conclude that at OCV certain amount of lithium ions have intercalated into the structure through chemical lithiation achieved by the surrounding of the active material in the lithium-containing acidic electrolyte prior to cell cycling.

Table 1. Crystal structure of cryptomelane $\mathrm{K}_{0.25} \mathrm{Mn}_{2} \mathrm{O}_{4}$ obtained from XRD data.

\begin{tabular}{llllllll}
\hline Atom & Valence & $\begin{array}{l}\text { Wyckoff } \\
\text { site }\end{array}$ & $x$ & $y$ & $z$ & $\begin{array}{l}\text { Atomic } \\
\text { Displacement } \\
\text { Parameter } \\
\left(\AA^{2}\right)\end{array}$ & $\begin{array}{l}\text { Site } \\
\text { Fccupancy }\end{array}$ \\
\hline $\mathrm{K}$ & +1 & $4 e$ & 0 & 0 & $3 / 8$ & $8.5(15)$ & 0.25 \\
$\mathrm{Mn}$ & +4 & $8 h$ & $0.351(1)$ & $0.167(1)$ & 0 & $2.2(1)$ & 0.75 \\
$\mathrm{Mn}$ & +3 & $8 h$ & $0.351(1)$ & $0.167(1)$ & 0 & $2.2(1)$ & 0.25 \\
$\mathrm{O}$ & -2 & $8 h$ & $0.132(1)$ & $0.194(1)$ & 0 & $1.7(6)$ & 1 \\
$\mathrm{O}$ & -2 & $8 h$ & $0.516(2)$ & $0.188(1)$ & 0 & $1.4(4)$ & 1 \\
\hline
\end{tabular}




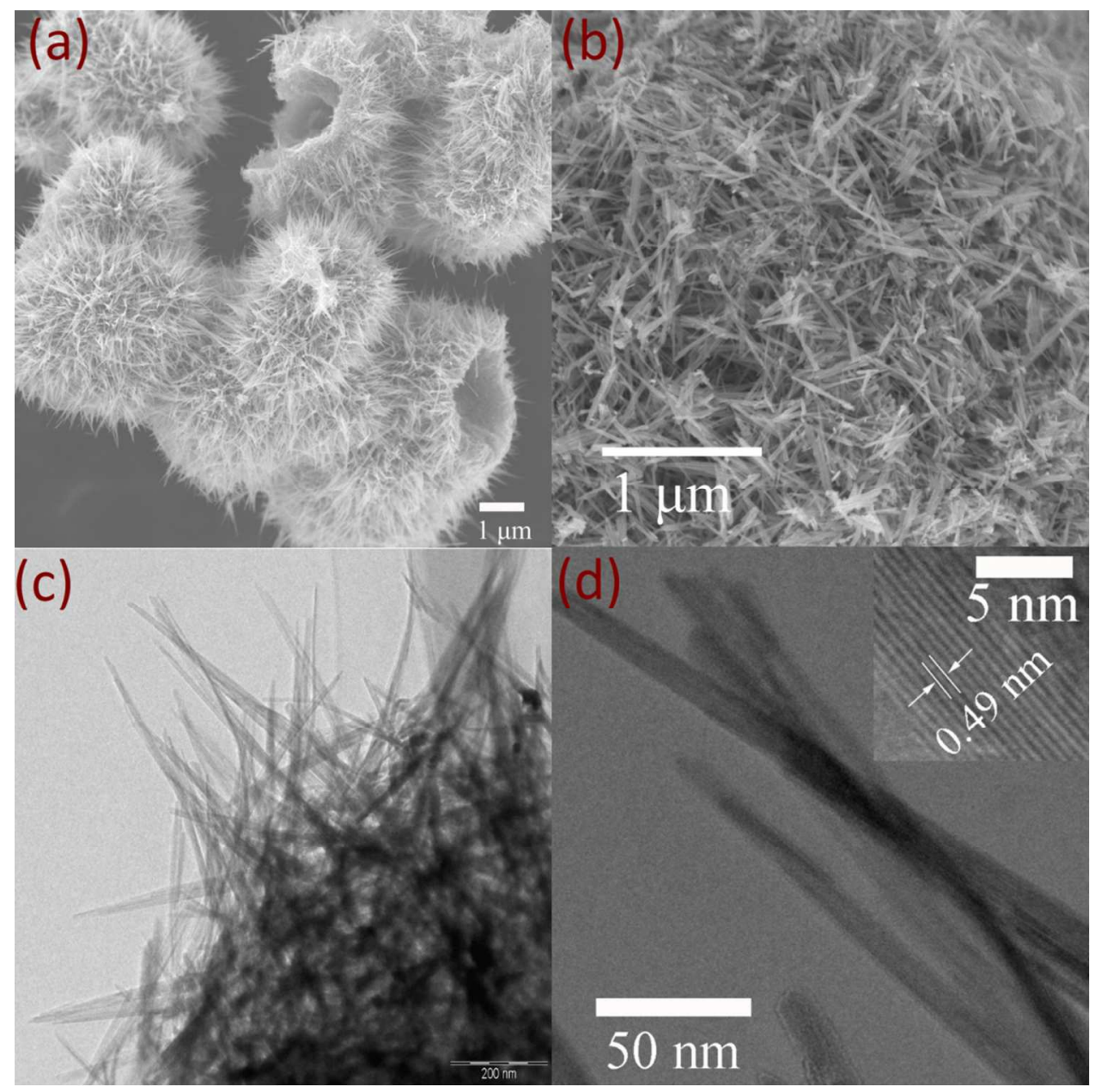

Figure 2. SEM micrographs of $\mathrm{K}_{\mathrm{x}} \mathrm{Mn}_{2} \mathrm{O}_{4}$ morphology showing (a) the cluster structure and (b) distribution of the whisker-like individual $\mathrm{K}_{\mathrm{x}} \mathrm{Mn}_{2} \mathrm{O}_{4}$ particles. (c) TEM micrograph of the cluster and (d) high-resolution image of the nano-whisker, inset shows the lattice fringe spacing of 0.49 $\mathrm{nm}$, the $\mathrm{K}_{\mathrm{x}} \mathrm{Mn}_{2} \mathrm{O}_{4} 020$ reflection. 


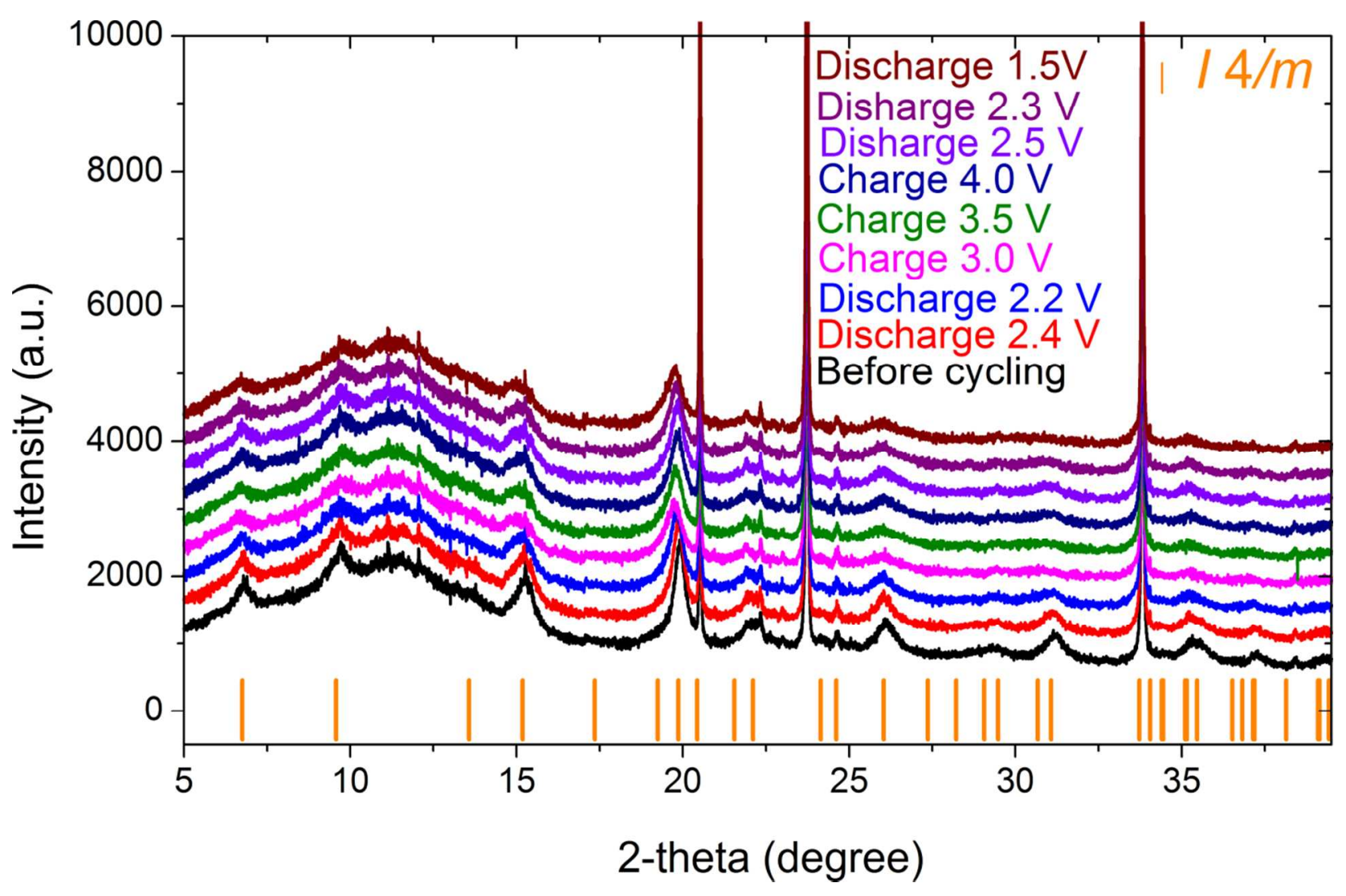

Figure 3. Stack of selected synchrotron X-ray diffraction patterns of the customized cell containing $\mathrm{K}_{\mathrm{x}} \mathrm{Mn}_{2} \mathrm{O}_{4}$ cathode and $\mathrm{Li}$ anode collected at various states of charge. The vertical bars show Bragg positions for the $\mathrm{K}_{\mathrm{x}} \mathrm{Mn}_{2} \mathrm{O}_{4}$ phase. 


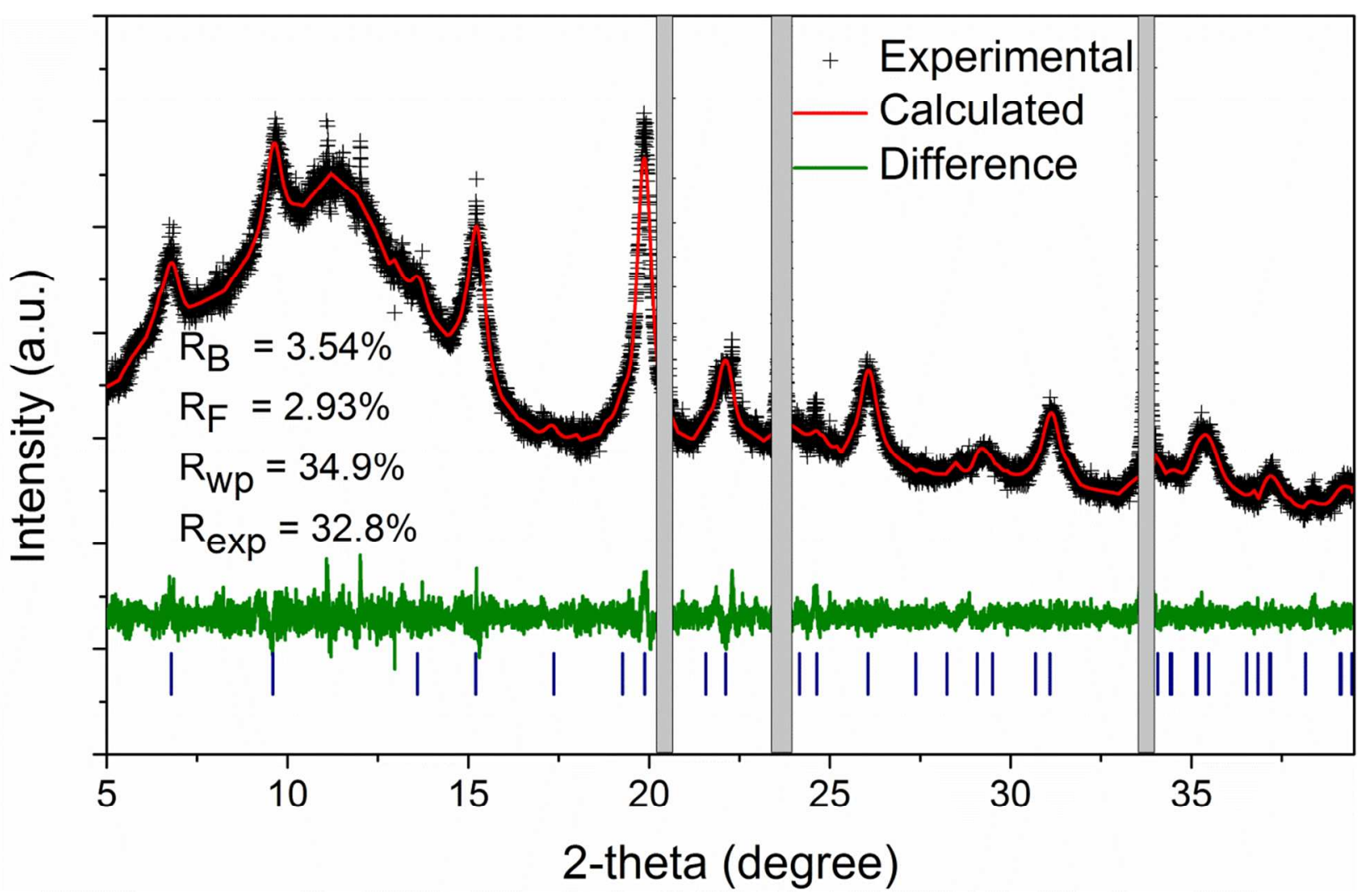

Figure 4. Rietveld-refined profile fit to SXRD data collected at OCV. The crosses $(+)$ represent the experimental data, the red solid-line is the calculated pattern, the green line is the difference between the experimental data and the calculated pattern, and the blue bars at the bottom show Bragg positions for the $\mathrm{K}_{\mathrm{x}} \mathrm{Mn}_{2} \mathrm{O}_{4}$ phase. The grey areas denote excluded regions where $\mathrm{Al}$ reflections are located.

The variations in lattice parameters and lattice volume upon lithiation and delithiation are shown in Figure 5. The lattice parameters $a(=b)$ and $c$ change to accommodate lithium ions. By implementing Vegard's law, ${ }^{17}$ the expansion and contraction of the lattice parameters $a$ and $c$ can be treated as a result of varying lithium occupation, thought to occur at $4 e$ sites in the structure, during cycling. During discharge (lithiation) it is expected that the lithium ions increasingly 
occupy the potassium or vacant sites with time. Given that the number of intercalated/deintercalated lithium ions are linearly proportional to the apparent capacity (or to time at a constant applied current), the lattice parameters $a$ and $c$ can be further considered as related to capacity. The lattice parameters and volume of the cryptomelane cathode alongside their rate of change, obtained during charge-discharge cycling of the battery are presented in Table 2. The capacity achieved in the discharge and charge processes is also calculated and shown in Figure S2.

Table 2. Cryptomelane lattice evolution during the lithiation-delithiation-lithiation process.

\begin{tabular}{|c|c|c|c|c|c|c|c|c|c|}
\hline \multirow[t]{2}{*}{ Process } & \multicolumn{2}{|c|}{$\begin{array}{l}\text { Lattice Parameter } \\
a \text { at the process } \\
\text { start and end }(\AA)\end{array}$} & \multicolumn{2}{|c|}{$\begin{array}{l}\text { Lattice } \\
\text { parameter } \\
c \text { at the process } \\
\text { start and end }(\AA)\end{array}$} & \multirow[t]{2}{*}{$\begin{array}{l}\text { Volu } \\
\text { me } \\
\text { chang } \\
\text { e } \\
\left(\AA^{3}\right)\end{array}$} & \multicolumn{2}{|l|}{$\begin{array}{l}\text { Rate of } \\
\text { change* } \\
(\AA / m A ~ h)\end{array}$} & \multirow{2}{*}{$\begin{array}{l}\text { Rate of } \\
\text { Volum } \\
\mathrm{e} \\
\text { change } \\
* \\
\left(\AA^{3} / \mathrm{m}\right. \\
\text { A h })\end{array}$} & \multirow[t]{2}{*}{$\begin{array}{l}\text { Curre } \\
\text { nt } \\
\text { applie } \\
\text { d } \\
(\mathrm{mA})\end{array}$} \\
\hline & Initial & Final & Initial & Final & & $a$ & $c$ & & \\
\hline $\begin{array}{l}\text { First } \\
\text { lithiatio } \\
\mathrm{n}\end{array}$ & $\begin{array}{l}9.9717( \\
4)\end{array}$ & $\begin{array}{l}10.0377 \\
(1)\end{array}$ & $\begin{array}{l}2.8738 \\
(2)\end{array}$ & $\begin{array}{l}2.9201 \\
(5)\end{array}$ & $\begin{array}{l}8.47( \\
7)\end{array}$ & $\begin{array}{l}2.49739 \\
(3)\end{array}$ & $\begin{array}{l}0.14315 \\
(8)\end{array}$ & $\begin{array}{l}28.739 \\
(8)\end{array}$ & $\begin{array}{l}- \\
0.574 \\
2\end{array}$ \\
\hline $\begin{array}{l}\text { First } \\
\text { delithiat } \\
\text { ion }\end{array}$ & $\begin{array}{l}10.0377 \\
(1)\end{array}$ & $\begin{array}{l}10.0107 \\
(8)\end{array}$ & $\begin{array}{l}2.9201 \\
(5)\end{array}$ & $\begin{array}{l}2.8815 \\
(3)\end{array}$ & $\begin{array}{l}5.45( \\
8)\end{array}$ & $\begin{array}{l}0.10972 \\
(5)\end{array}$ & $\begin{array}{l}0.17241 \\
(3)\end{array}$ & $\begin{array}{l}23.761 \\
(3)\end{array}$ & $\begin{array}{l}+0.57 \\
42\end{array}$ \\
\hline $\begin{array}{l}\text { Second } \\
\text { lithiatio } \\
n\end{array}$ & $\begin{array}{l}10.0107 \\
(8)\end{array}$ & $\begin{array}{l}10.0353 \\
(9)\end{array}$ & $\begin{array}{l}2.8815 \\
(3)\end{array}$ & $\begin{array}{l}2.9233 \\
(5)\end{array}$ & $\begin{array}{l}5.63( \\
9)\end{array}$ & $\begin{array}{l}0.10763 \\
(6)\end{array}$ & $\begin{array}{l}0.14315 \\
(9)\end{array}$ & $\begin{array}{l}20.625 \\
(9)\end{array}$ & $\begin{array}{l}- \\
0.574 \\
2\end{array}$ \\
\hline
\end{tabular}

* The rate of change is determined by linear least-squares linear to the time evolution of the lattice parameter. Fit profiles and figures of merit are shown in Figure S3. 


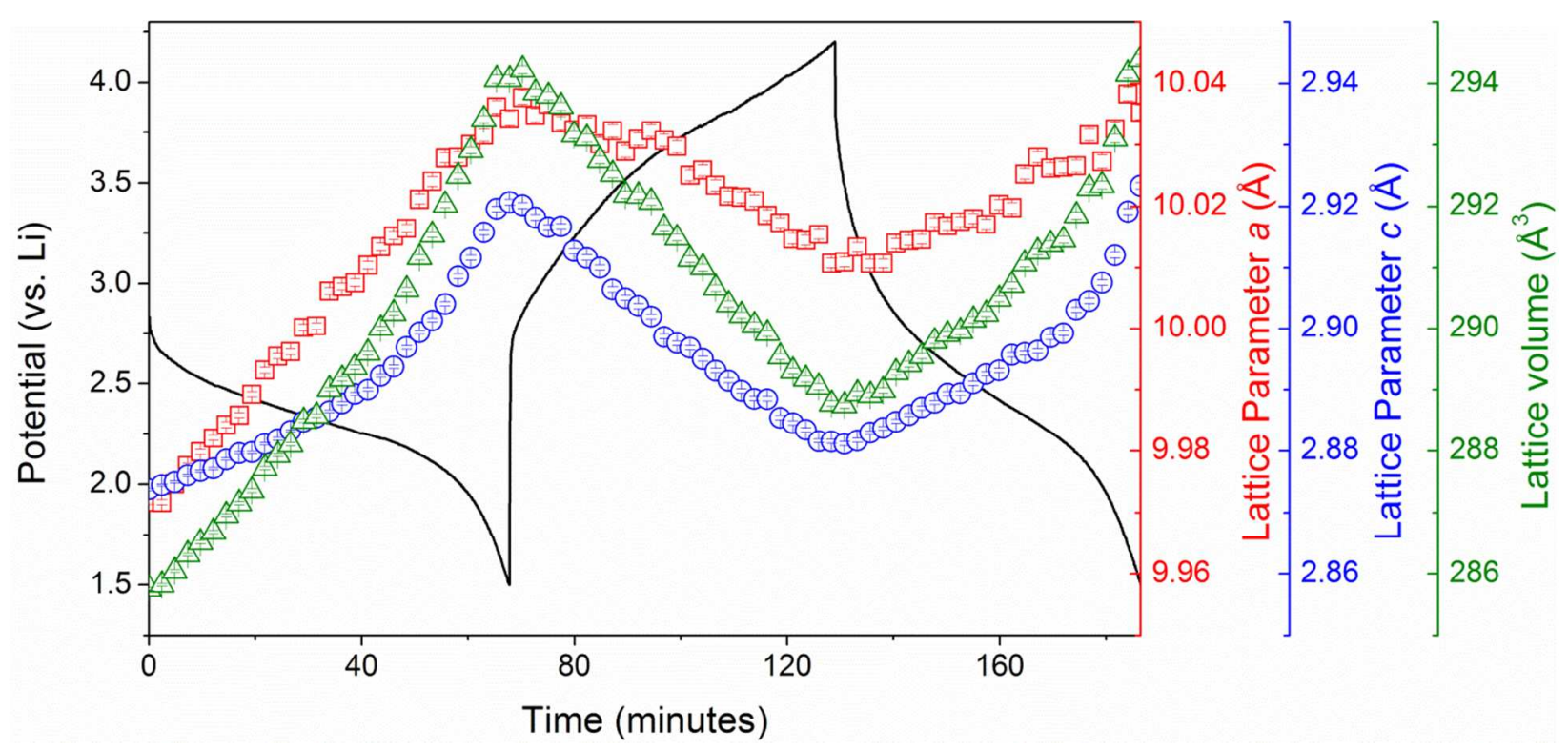

Figure 5. Lattice parameters and volume of cryptomelane as determined from the sequential Rietveld refinement of the $\mathrm{K}_{\mathrm{X}} \mathrm{Mn}_{2} \mathrm{O}_{4}$ structure upon lithiation and delithiation using SXRD. The discharge-charge profile is also shown.

As expected, we observe a lattice expansion upon intercalation of lithium ions into the cryptomelane structure. The lattice parameters are correlated to both the diameter and length of the pore channels though to accommodate lithium diffusion. During initial lithiation of a fresh cryptomelane-containing battery, lithium ions intercalate and occupy the tunnel vacancies while the potassium ions are still present. According to Zhang et al. ${ }^{16}$ at this point mixed $\mathrm{Li} / \mathrm{K}$ occupation exists at the $4 e$ sites, contributing to the increase in lattice parameters and volume that we observe. The change in lattice parameters between the charges and discharged state during the first lithiation are $0.66(5) \%$ and $1.61(5) \%$ for $a$ and $c$ parameters, respectively, and the change in the lattice volume for this process is $2.96(8) \%$, ranging from a maximum of 294.22(7) $\AA^{3}$ to a minimum of $285.75(2) \AA^{3}$. From the absolute changes in lattice parameters, the lithium 
intercalation at the $4 e$ site induces a larger expansion of the $a b$ plane relative to the $a c$ or $b c$ planes. A schematic diagram illustrating the change of $a b$ plane of the unit cell on going from the OCV discharged state to the charged state is shown in Figure 6 (close-up views of the crystal plane are shown as subfigure). The lattice parameters are also affected by the cooperative JahnTeller distortion, as a result of the changing ratio of $\mathrm{Mn}^{3+}$ to $\mathrm{Mn}^{4+}$, which is higher upon lithiation. With the potassium still in place, the number of lithium ion that can be intercalated is restricted, restraining the Jahn-Teller distortion at the expense of capacity.

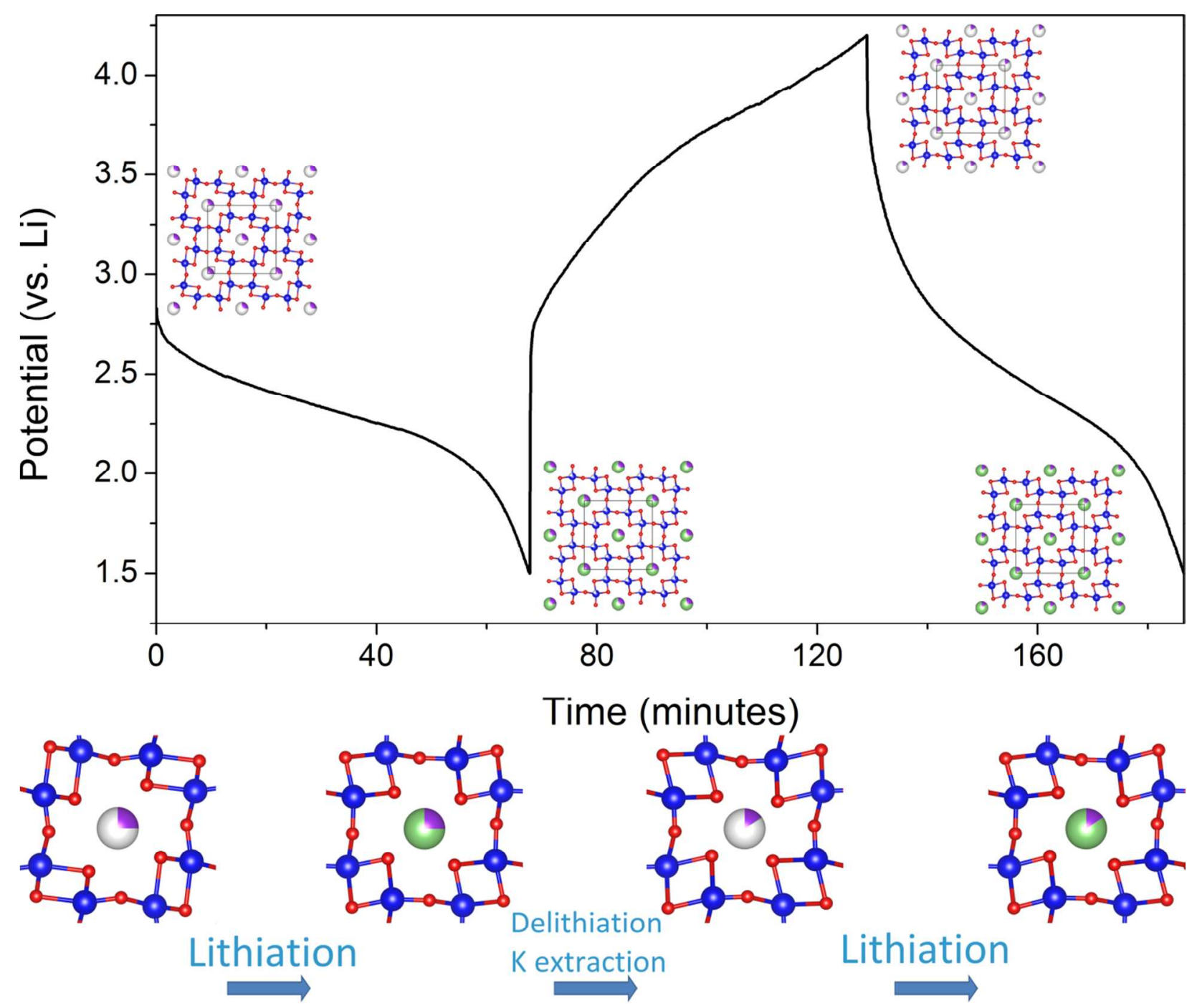


Figure 6. Schematic illustration in the $a b$ plane of the $\mathrm{Li}_{\mathrm{x}-\mathrm{y}} \mathrm{K}_{0.25-\mathrm{m}} \mathrm{Mn}_{2} \mathrm{O}_{4}$ at various states. The crystal structures of the $\mathrm{Li}_{\mathrm{x}-\mathrm{y}} \mathrm{K}_{0.25-\mathrm{m}} \mathrm{Mn}_{2} \mathrm{O}_{4}$ are plotted based on the Rietveld refinement result using selected patterns. The bottom figure details the $4 e$-site occupation in the structure and the variation of the tunnel size. Bond lengths and distorted angle are measured and summarized in Table S2.

On delithiation, potassium ions are partially extracted along with lithium ions and both are dissolved in the electrolyte. ${ }^{16}$ As a consequence, the lattice contracts to $288.77(5) \AA^{3}$, which is still larger than the OCV lattice and this appears to be at odds with potassium removal from the structure (e.g. the removal of all lithium and some potassium ions should result in a smaller lattice than that observed at OCV, following Vegard's law). An explanation for the larger lattice at apparently lower lithium and potassium concentrations is that a significant amount of lithium remains in the structure. By assuming some potassium extraction ${ }^{16}$ and considering the larger lattice of the electrode at this state, the composition of the electrode is theoretically predicted to be $\mathrm{Li}_{x-y} \mathrm{~K}_{0.25-m} \mathrm{Mn}_{2} \mathrm{O}_{4}$ with $x>y+m$. The remaining lithium in the structure is also evidenced by the measured capacity loss, where we find $0.65 \mathrm{~mA} \mathrm{~h}\left(2.43 \times 10^{-5} \mathrm{~mol}\right.$ lithium ions $)$ for the first lithiation but only $0.59 \mathrm{~mA} \mathrm{~h}\left(2.20 \times 10^{-5} \mathrm{~mol}\right.$ lithium ions $)$ for the first delithiation. Morever, the variation of the $a$ and $c$ lattice parameters differ from each other. The lithium (and potassium) extraction from $4 e$ sites result in a relative larger contraction of the lattice parameter $c$, in comparison to the $a$ and $b$ parameters. The non-uniform contractions may suggest that the capacity is not only carried by delithiation, but also potassium extraction from the host structure. Additionally, the rate of change of the $a$ lattice parameter during the second lithiation is $50 \%$ less than that of the first lithiation. In other words, with a lower potassium content in the electrode, 
the lithium insertion and extraction exhibits a greater influence on the $c$ than on the $a$ lattice parameter.

On second lithiation, the number of remaining potassium ions is supposedly unchanged in the structure and no further potassium ions are inserted. Upon lithium insertion, the cryptomelane structure expands with increasing lithium occupation at the $4 e$ site. The rate of change of the lattice parameter $a$ is nearly the same as that of the previous delithiation process, indicating a greater stability in the reversibility of lithium insertion/desertion in the structure, with the remaining potassium in the cathode acting effectively as a spectator to these processes. The monotonic change in the lattice parameter $a$ with lithium occupation is expected as a result of the stable $\mathrm{MnO}_{6}$ framework, allowing for good cycling stability during charge-discharge. Nevertheless, the least-squares residual of linear fits to the variation of lattice parameter $c$ with lithium occupation, especially at high lithium concentrations, indicates a deviation from linearity, suggesting that the lattice distortion is more pronounced at higher $\mathrm{Mn}^{3+}$ (and $\mathrm{Li}^{+}$) concentrations. As shown in Table 2, the variation of the lattice parameter $a$, related to the size of the tunnels available for ionic diffusion, increases linearly with the amount of intercalated lithium ions. A figure detailing the $4 e$-site occupation in the structure and the variation of the tunnel size are shown in Figure 6. Considering Vegard's law, the non-linearity in the relationship between lithium content and the lattice parameter $c$ suggests the present of lattice distortion caused by a change in bonding, likely as a result of Jahn-Teller effects. These effects can be considered in two parts of the lithiation processes - the first $2 / 3$ and the last $1 / 3$ of the process, forming two different reaction mechanisms of lithium intercalation in cryptomelane structure (see Figure $\mathrm{S} 3 \mathrm{~b})$. Here we see an increase in the non-uniformity of Jahn-Teller distortion, accompanied by 
anisotropic expansion and contract of the $a$ and $c$ axes that suggest that the Jahn-Teller induced strains vary in different directions.

The anisotropy of the expansion is clearly revealed from single-peak fitting of the SXRD data. The results of Gaussian peak fitting to the cryptomelane 130 and 121 reflections are presented in Figure 7 (a-c). As expected, these reflections shift to lower angles during discharge (lithiation) and to higher angles during charge (delithiation), as consistent with the lattice parameter changes determined above. Interestingly, the intensity (height) of both reflections decreases with the amount of intercalated lithium, however, simulated patterns with lithium occupancy at the $4 e$ sites suggest that the integrated intensity should increase slightly (Figure 8). We first focus on the cryptomelane 130 reflection, where calculations show that extraction of $\mathrm{K}^{+}$from the structure results in a decrease in reflection intensity. Comparison of the 130 reflection intensity in the SXRD data between the two discharged states (at 68 and $186 \mathrm{~min}$ ) reveals a significantly lower reflection intensity at $186 \mathrm{~min}$ than at $68 \mathrm{~min}$, further evidencing the extraction of $\mathrm{K}^{+}$ions during the first delithiation process. Regarding cryptomelane 121 reflection intensity, the decrease is compensated by the increase of FWHM, providing a nearly unchanged integrated intensity. It notes that the simulated patterns are calculated at fixed peak-shape parameters. These reflections broaden, which is consistent with strain induced by the presence of an increasing amount of distorted $\mathrm{Mn}^{3+} \mathrm{O}_{6}$ octahedra as a result of Jahn-Teller effects during lithiation. As the $\mathrm{Mn}^{3+}$ concentration changes during cycling, the degree (and strength) of Jahn-Teller effects also vary. As a consequence, there is significant strain during lithium insertion and desertion that is commensurate with $\mathrm{MnO}_{6}$ octahedral distortion (see Figure 6). The strain-induced peak broadening is modeled and quantified using the reflection FWHM as shown in Equation 4 and the results are shown in Figure 9. The strain as measured using the cryptomelane 130 and 121 
reflections increases and decreases with the lithium occupation during lithiation and delithiation, respectively. Moreover, the variation of strain along the [121] direction is found to be significantly larger than that of the [130] direction during lithiation and delithiation. The reversibility of the strain suggests that the cryptomelane cathode will exhibit good cycling stability, a very useful property for lithium ion battery application, despite the significant JahnTeller distortion.

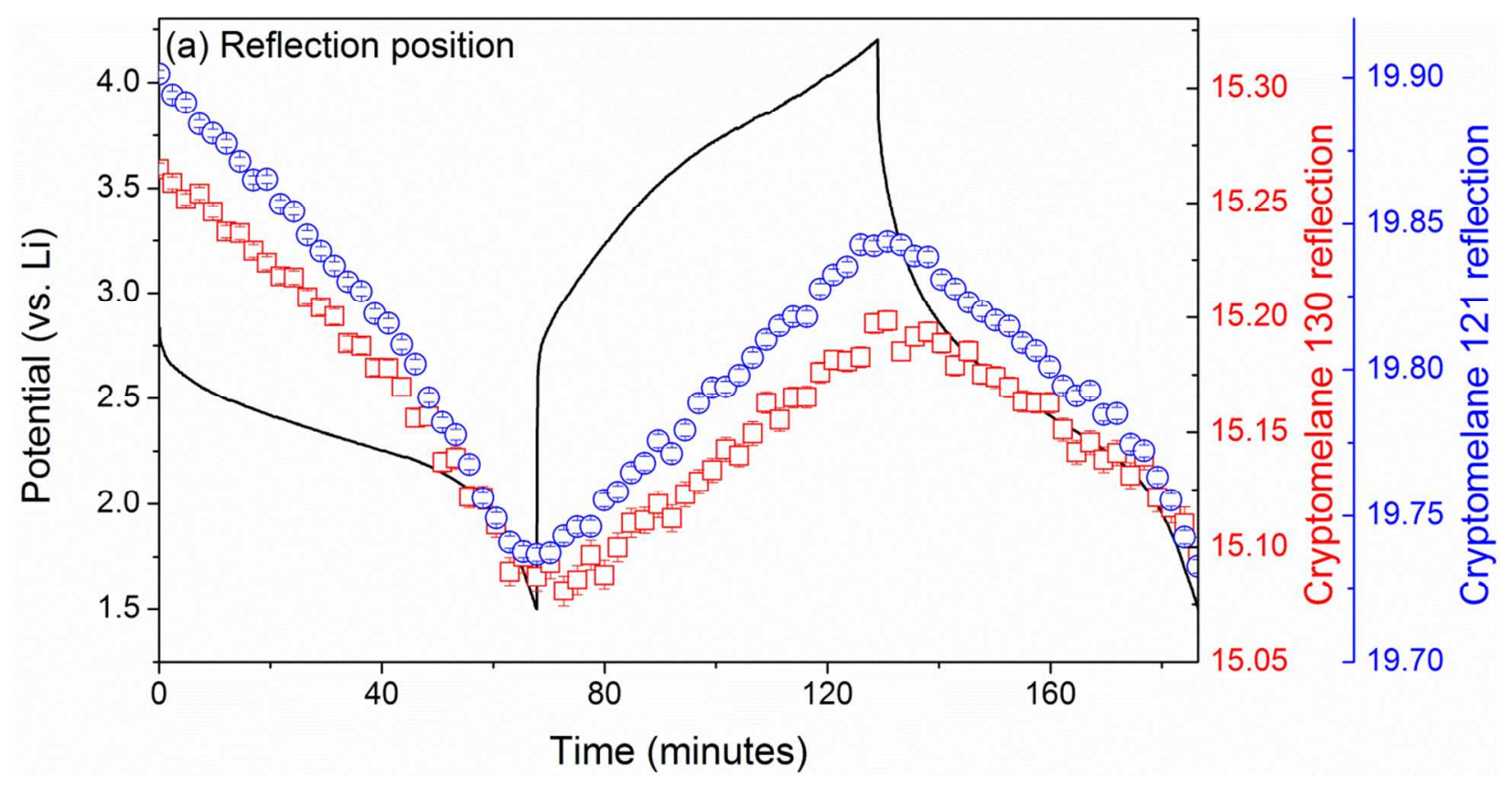



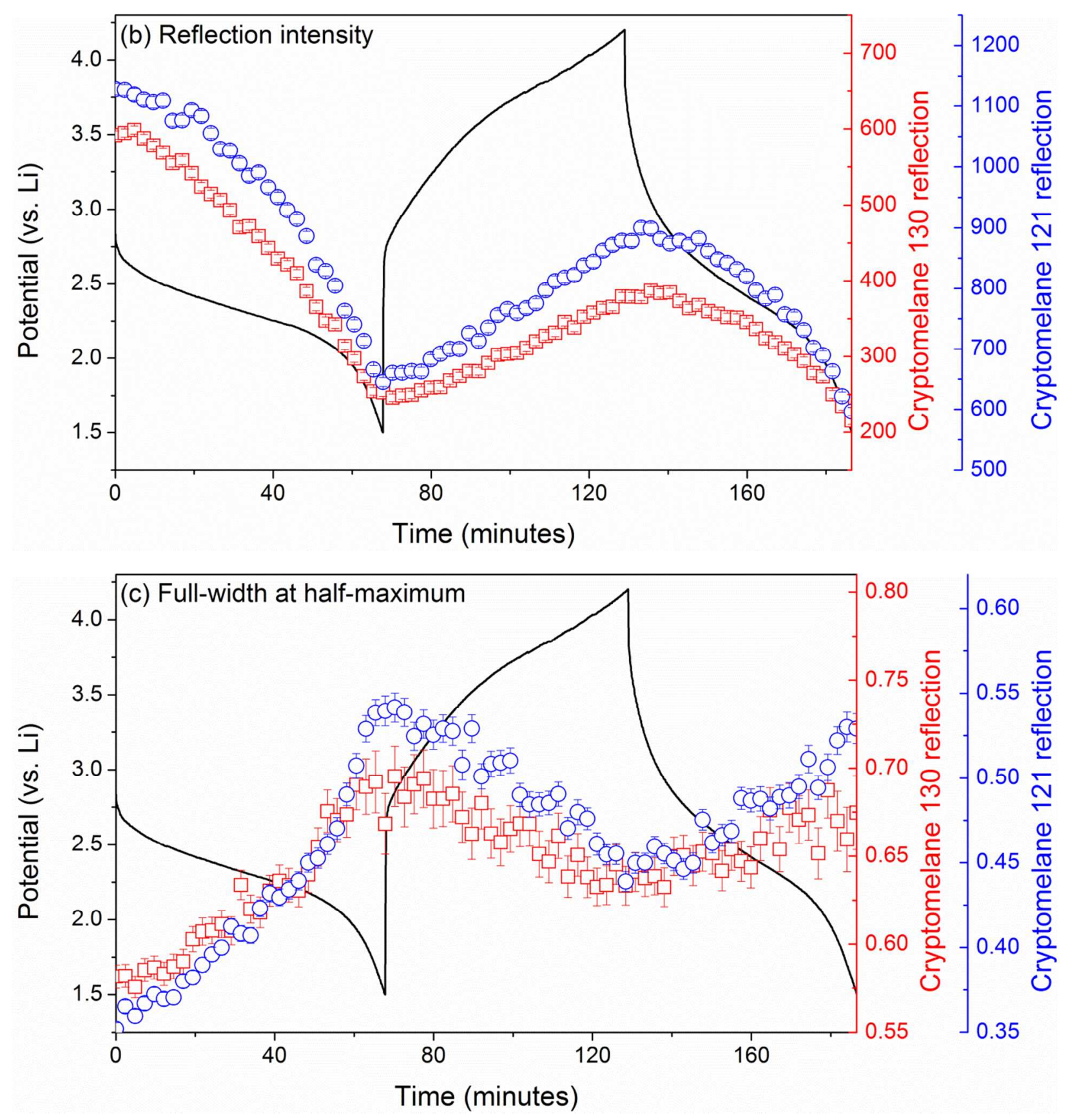

Figure 7. Single-peak fitting results showing the variation of (a) position, (b) intensity, and (c) FWHM of the cryptomelane 130 and 121 reflections. 


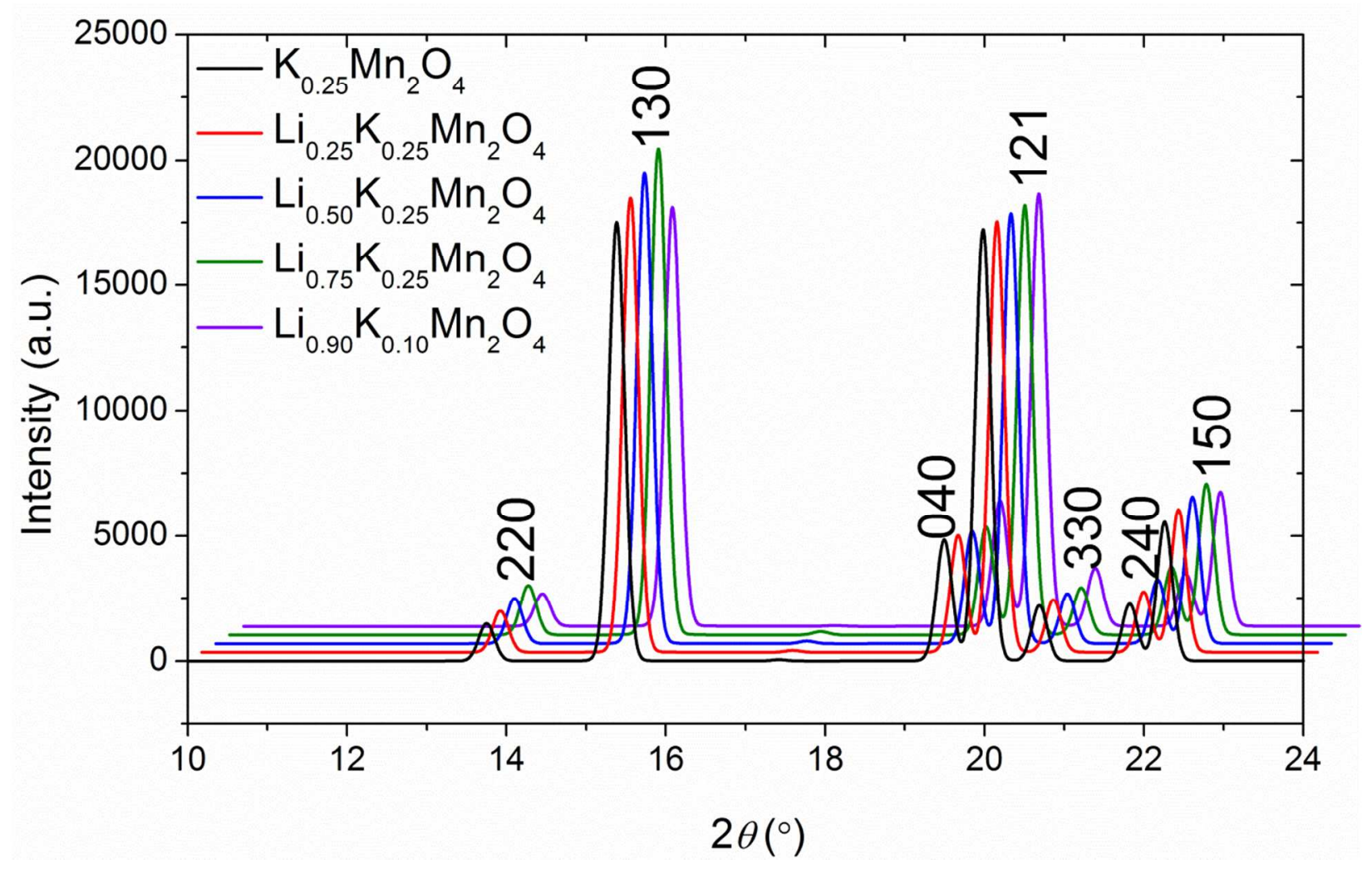

Figure 8. Calculated XRD patterns of $\mathrm{Li}_{\mathrm{x}-\mathrm{y}} \mathrm{K}_{0.25-\mathrm{m}} \mathrm{Mn}_{2} \mathrm{O}_{4}$ at a wavelength of $0.8352 \AA$ (that used in the SXRD experiments) using a fixed peak shape. Reflections are labeled. Offsets are applied for both $\mathrm{x}$ and $\mathrm{y}$ axes for ease of comparison. 


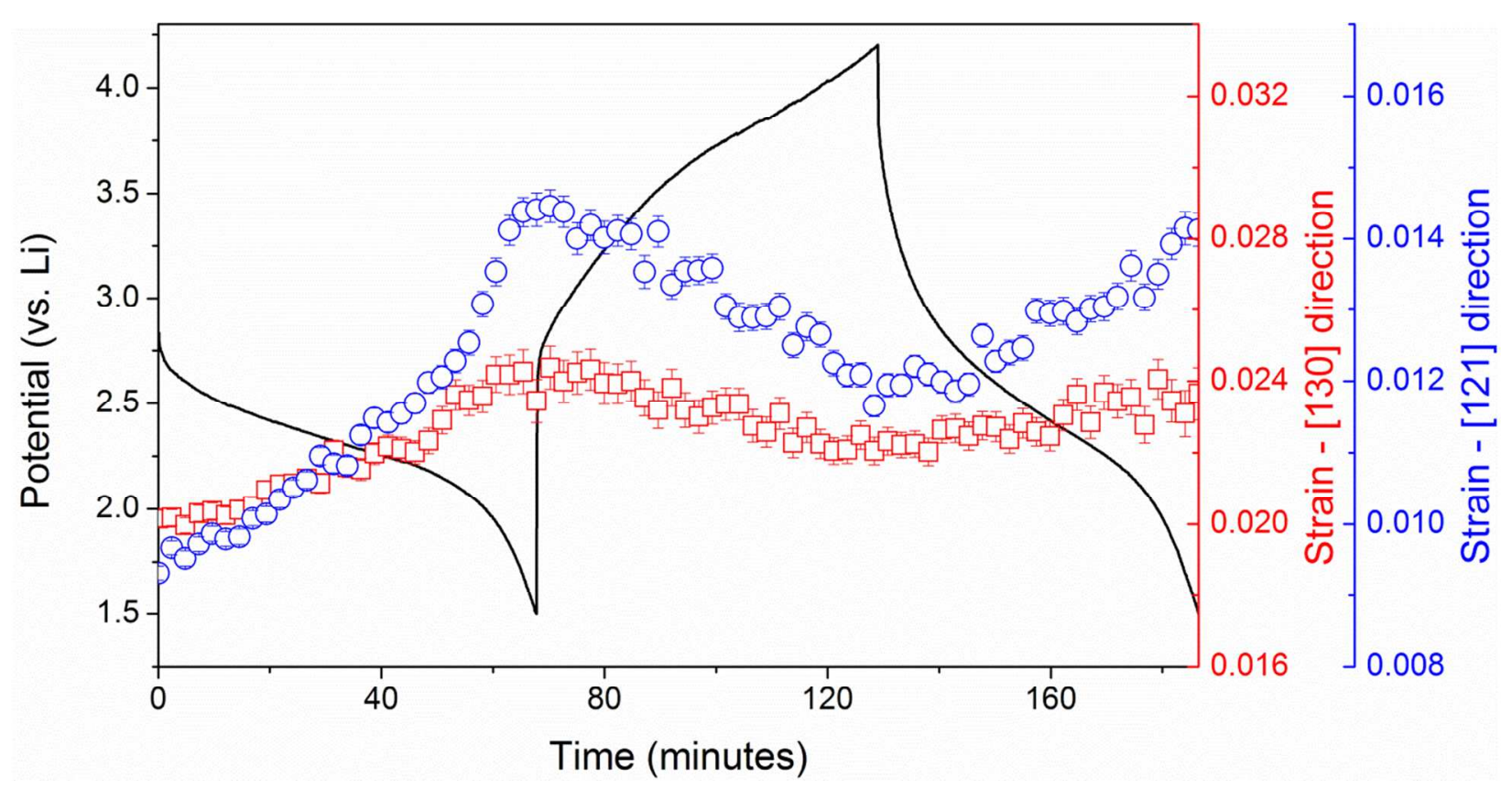

Figure 9. Variation of Jahn-Teller distortion-induced strain upon cycling.

\section{CONCLUSIONS}

The structural evolution of the cryptomelane cathode in a custom-made lithium ion battery during cycling (lithiation and delithiation) is investigated using in-situ synchrotron X-ray powder diffraction. A solid-solution reaction mechanism and an associated Jahn-Teller distortioninduced strain were found to take place when lithium ions intercalate into and deintercalate from the cryptomelane. Details of the structural evolution of the cryptomelane are gained from both single-peak fitting and Rietveld analysis. Both $a$ and $c$ lattice parameters expand with lithium intercalation and contract with lithium deintercalation. The variation of the lattice parameter $a$ reveals that the size of tunnels in the cryptomelane structure available for lithium diffusion increases linearly with the amount of intercalated lithium. Further, deviation from linearity in the relationship between lithium content and the lattice parameter $c$ suggests the present of lattice distortion as a result of reversible Jahn-Teller distortion, which we quantify in terms of the non- 
uniform weighted average strain along the [130] and [121] directions in the structure. The variation of the strain along the [121] direction is found to be significantly larger than that of [130] direction during lithiation and delithiation, in good agreement with both the deviation from linearity observed for the lattice parameter $c$ and the capacity measurement (lithium concentration). Taken together, these results suggest that the cryptomelane $\mathrm{K}_{0.25} \mathrm{Mn}_{2} \mathrm{O}_{4}$ microclusters we study are an excellent candidate cathode material for use in lithium-ion batteries.

\section{AUTHOR INFORMATION}

\section{Corresponding Author}

* Email: pwk1980@yahoo.com (W.K.P.)

* Email: zguo@uow.edu.au (Z.G.). Tel: +61 24221 5225, Fax: +61 242215731

* School of Mechanical, Materials, and Mechatronic Engineering, Institute for Superconducting \& Electronic Materials, Faculty of Engineering, University of Wollongong, NSW 2522, Australia.

\section{Author Contributions}

The manuscript was written through contributions of all authors. All authors have given approval to the final version of the manuscript.

\section{Notes}

The authors declare no competing financial interest.

\section{ACKNOWLEDGMENT}


Financial support provided by the Australian Research Council (ARC) through an ARC Discovery project (DP1094261) is gratefully acknowledged. This research was undertaken on the Powder Diffraction beamline at the Australian Synchrotron, Victoria, Australia. The authors are also thankful to the instrumental supports by Dr. Justin Kimpton and Dr. Qinfen Gu of Australian Synchrotron.

\section{SUPPORTING INFORMATION}

Laboratory XRD pattern of the as-prepared $\mathrm{K}_{0.25} \mathrm{Mn}_{2} \mathrm{O}_{4}$ microclusters and profile fitted using an $I 4 / m$ structure (Figure S1), discharge-charge profiles of the $\mathrm{K}_{0.25} \mathrm{Mn}_{2} \mathrm{O}_{4}$ cathode within a voltage window of 1.5 and $4.2 \mathrm{~V}$ (vs. Li) (Figure S2), linear least-square fits to the time evolution of lattice parameters (Figure S3), figure-of-merits for sequential refinement results (Table S1), and bond lengths and distorted angle of Mn-O octahedron (Table S2). This material is available free of charge via the Internet at http://pubs.acs.org.

\section{REFERENCES}

(1) Tarascon, J. M.; Armand, M. Issues and Challenges Facing Rechargeable Lithium Batteries. Nature 2001, 414, 359-367.

(2) Armand, M.; Tarascon, J. M. Building Better Batteries. Nature 2008, 451, 652657.

(3) Thackeray, M. M.; Rossouw, M. H.; de Kock, A.; de la Harpe, A. P.; Gummow, R. J.; Pearce, K.; Liles, D. C. The Versatility of $\mathrm{MnO}_{2}$ for Lithium Battery Applications. $J$. Power Sources 1993, 43, 289-300.

(4) Reddy, M. V.; Subba Rao, G. V.; Chowdari, B. V. R. Metal Oxides and Oxysalts as Anode Materials for Li Ion Batteries. Chem. Rev. 2013, 113, 5364-5457.

(5) Wang, D.; Liu, L. M.; Zhao, S. J.; Li, B. H.; Liu, H.; Lang, X. F. $\beta-\mathrm{MnO}_{2}$ as A Cathode Material for Lithium Ion Batteries from First Principles Calculations. Phys. Chem. Chem. Phys. 2013, 15, 9075-9083.

(6) Ceder, G.; Mishra, S. K. The Stability of Orthorhombic and Monoclinic-Layered $\mathrm{LiMnO}_{2}$. Electrochem. Solid-State Lett. 1999, 2, 550-552. 
(7) Spahr, M. E.; Novák, P.; Scheifele, W.; Haas, O.; Nesper, R. Electrochemistry of Chemically Lithiated $\mathrm{NaV}_{3} \mathrm{O}_{8}$ : A Positive Electrode Material for Use in Rechargeable LithiumIon Batteries. J. Electrochem. Soc. 1998, 145, 421-427.

(8) Chen, R.; Whittingham, M. S. Cathodic Behavior of Alkali Manganese Oxides from Permanganate. J. Electrochem. Soc. 1997, 144, L64-L67.

(9) Liu, H.; Wang, Y.; Li, L.; Wang, K.; Hosono, E.; Zhou, H. Facile Synthesis of $\mathrm{NaV}_{6} \mathrm{O}_{15}$ Nanorods and Its Electrochemical Behavior as Cathode Material in Rechargeable Lithium Batteries. J. Mater. Chem. 2009, 19, 7885-7891.

(10) Ahn, D.; Yoo, I.; Koo, Y.-M.; Shin, N.; Kim, J.; Shin, T. J. Effects of Cobaltintercalation and Polyaniline Coating on Electrochemical Performance of Layered Manganese Oxides. J. Mater. Chem. 2011, 21, 5282-5289.

(11) Gao, T.; Glerup, M.; Krumeich, F.; Nesper, R.; Fjellvåg, H.; Norby, P. Microstructures and Spectroscopic Properties of Cryptomelane-type Manganese Dioxide Nanofibers. J. Phys. Chem. C 2008, 112, 13134-13140.

(12) Huang, H.; Sithambaram, S.; Chen, C.-H.; King'ondu Kithongo, C.; Xu, L.; Iyer, A.; Garces, H. F.; Suib, S. L. Microwave-Assisted Hydrothermal Synthesis of CryptomelaneType Octahedral Molecular Sieves (OMS-2) and Their Catalytic Studies. Chem. Mater. 2010, 22, 3664-3669.

(13) Hu, B.; Chen, C.-h.; Frueh, S. J.; Jin, L.; Joesten, R.; Suib, S. L. Removal of Aqueous Phenol by Adsorption and Oxidation with Doped Hydrophobic Cryptomelane-Type Manganese Oxide (K-OMS-2) Nanofibers. J. Phys. Chem. C 2010, 114, 9835-9844.

(14) Opembe, N. N.; King'ondu, C. K.; Espinal, A. E.; Chen, C.-H.; Nyutu, E. K.; Crisostomo, V. M.; Suib, S. L. Microwave-Assisted Synthesis of Manganese Oxide Octahedral Molecular Sieve (OMS-2) Nanomaterials under Continuous Flow Conditions. J. Phys. Chem. C 2010, 114, 14417-14426.

(15) Galindo, H.; Carvajal, Y.; Njagi, E.; Ristau, R.; Suib, S. Facile One-step Template-free Synthesis of Uniform Hollow Microstructures of Cryptomelane-type Manganese Oxide K-OMS-2. Langmuir 2010, 26, 13677-13683.

(16) Zhang, C.; Feng, C.; Zhang, P.; Guo, Z.; Chen, Z.; Li, S.; Liu, H. $\mathrm{K}_{0.25} \mathrm{Mn}_{2} \mathrm{O}_{4}$ Nanofiber Microclusters as High Power Cathode Materials for Rechargeable Lithium Batteries. RSC Adv. 2012, 2, 1643-1649.

(17) Denton, A. R.; Ashcroft, N. W. Vegard's Law. Phys. Rev. A 1991, 43, 3161-3164.

(18) Vicat, J.; Fanchon, E.; Strobel, P.; Tran Qui, D. The Structure of $\mathrm{K}_{1.33} \mathrm{Mn}_{8} \mathrm{O}_{16}$ and Cation Ordering in Hollandite-type Structures. Acta Crystallogr. Sect. B 1986, 42, 162-167.

(19) Hunter, B.; International Union of Crystallography Commission on Powder Diffraction Newsletter No. 20, (Summer) http://www.rietica.org: 1998.

(20) Richard, D.; Ferrand, M.; Kearley, G. J. Analysis and Visualisation of Neutronscattering Data. J. Neutron Res. 1996, 4, 33-39.

(21) Rodríguez-Carvajal, J. Recent Advances in Magnetic Structure Determination by Neutron Powder Diffraction. Physica B 1993, 192, 55-69.

(22) T. Roisnel; Rodriguez-Carvajal, J. In Materials Science Forum, Proceedings of the Seventh European Powder Diffraction Conference (EPDIC 7); R. Delhez, Mittenmeijer, E. J., Eds. 2000, p 118-123.

(23) Patterson, A. L. The Scherrer Formula for X-Ray Particle Size Determination. Phys. Rev. 1939, 56, 978-982. 
1

2

3

4

5

6

7

8

9

10

11

12

13

14

15

16

17

18

19

20

21

22

23

24

25

26

27

28

29

30

31

32

33

34

35

36

37

38

39

40

41

42

43

44

45

46

47

48

49

50

51

52

53

54

55

56

57

58

59

60

(24) Sharma, N.; Reddy, M. V.; Du, G.; Adams, S.; Chowdari, B. V. R.; Guo, Z.; Peterson, V. K. Time-Dependent in-Situ Neutron Diffraction Investigation of a $\mathrm{Li}\left(\mathrm{Co}_{0.16} \mathrm{Mn}_{1.84}\right) \mathrm{O}_{4}$ Cathode. J. Phys. Chem. C 2011, 115, 21473-21480. 
Table of Contents
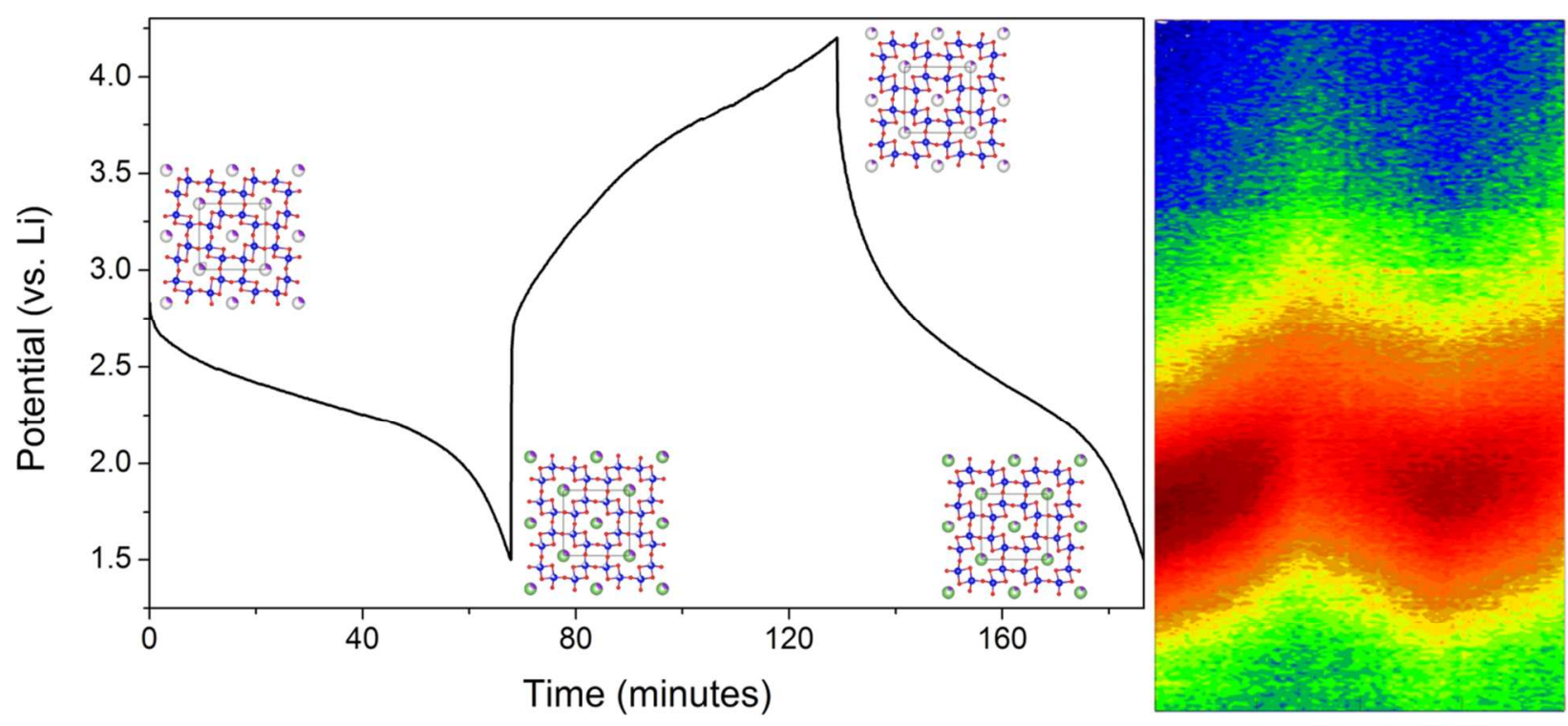

In-situ SXRD
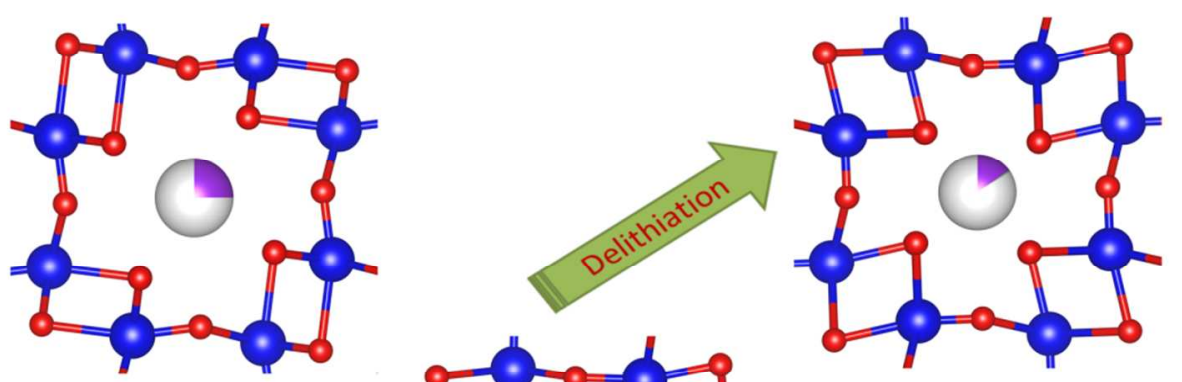

patterns
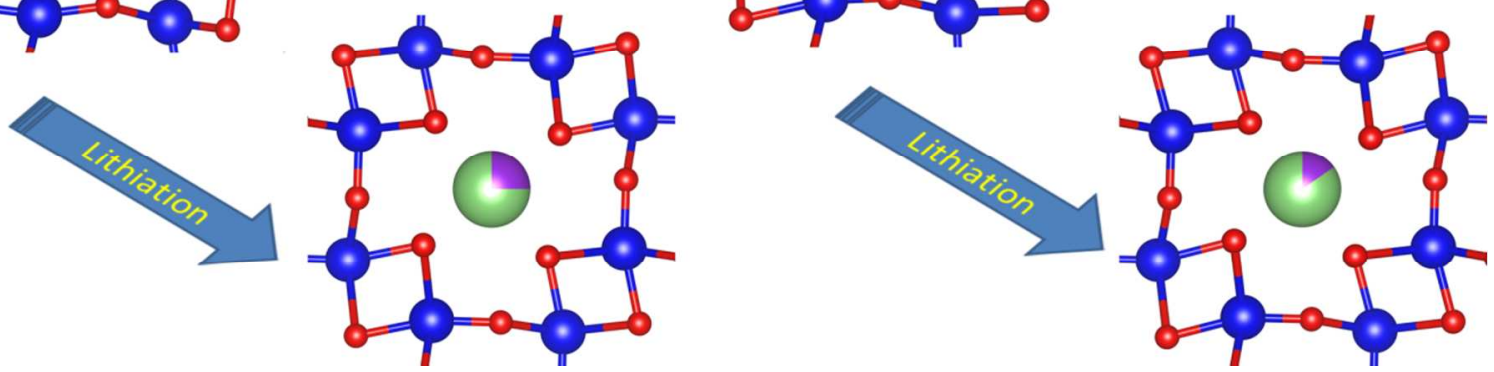


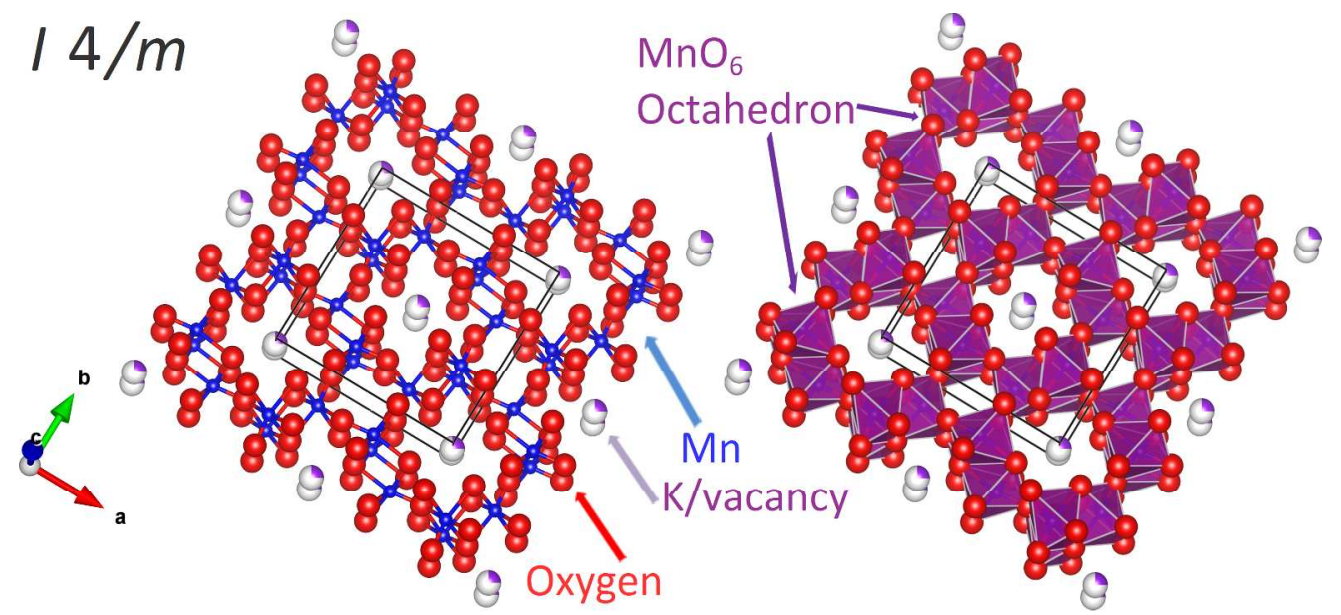

Figure 1

$258 \times 118 \mathrm{~mm}(300 \times 300$ DPI $)$ 


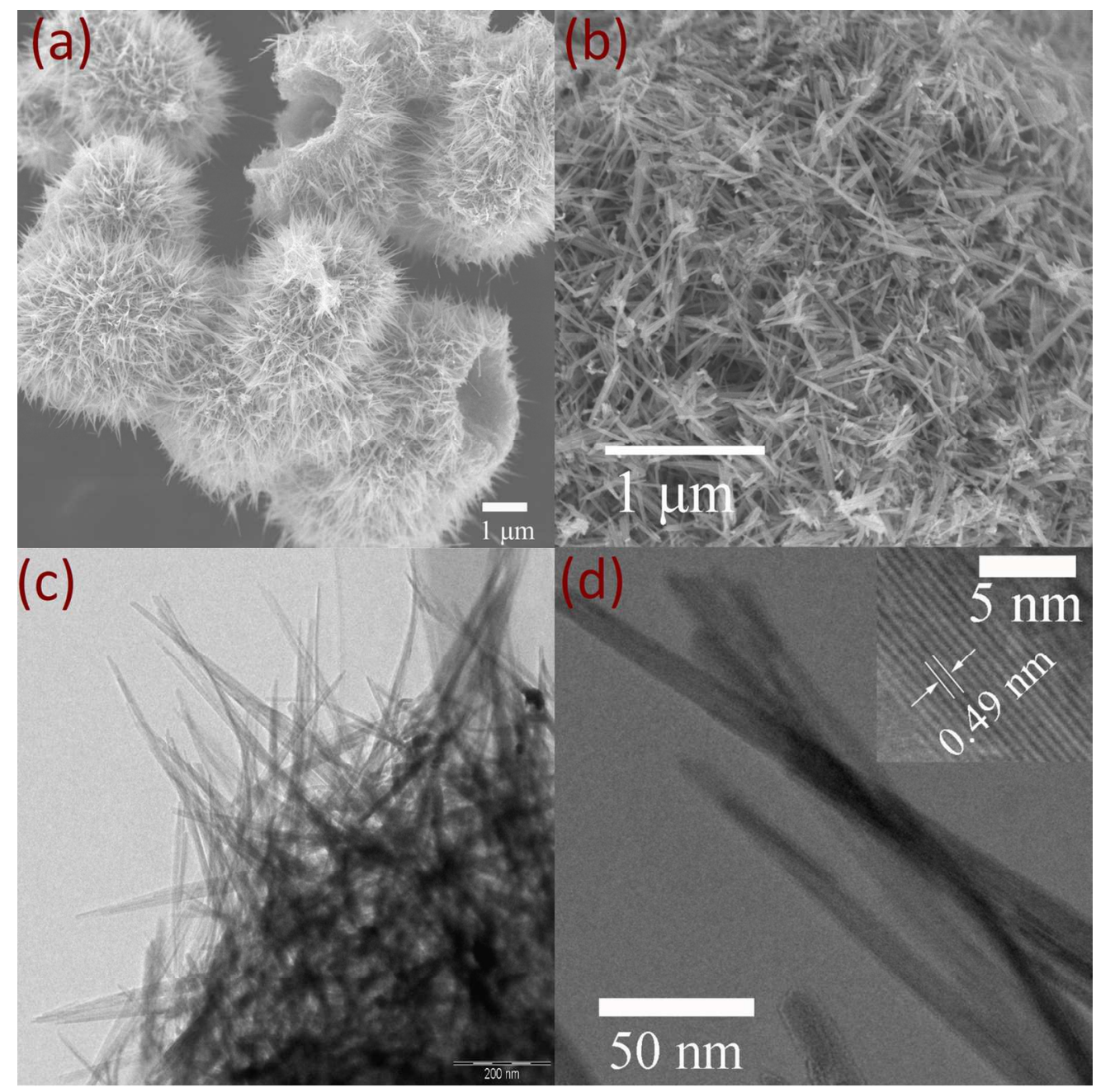

Figure 2

$127 \times 127 \mathrm{~mm}(300 \times 300$ DPI $)$ 


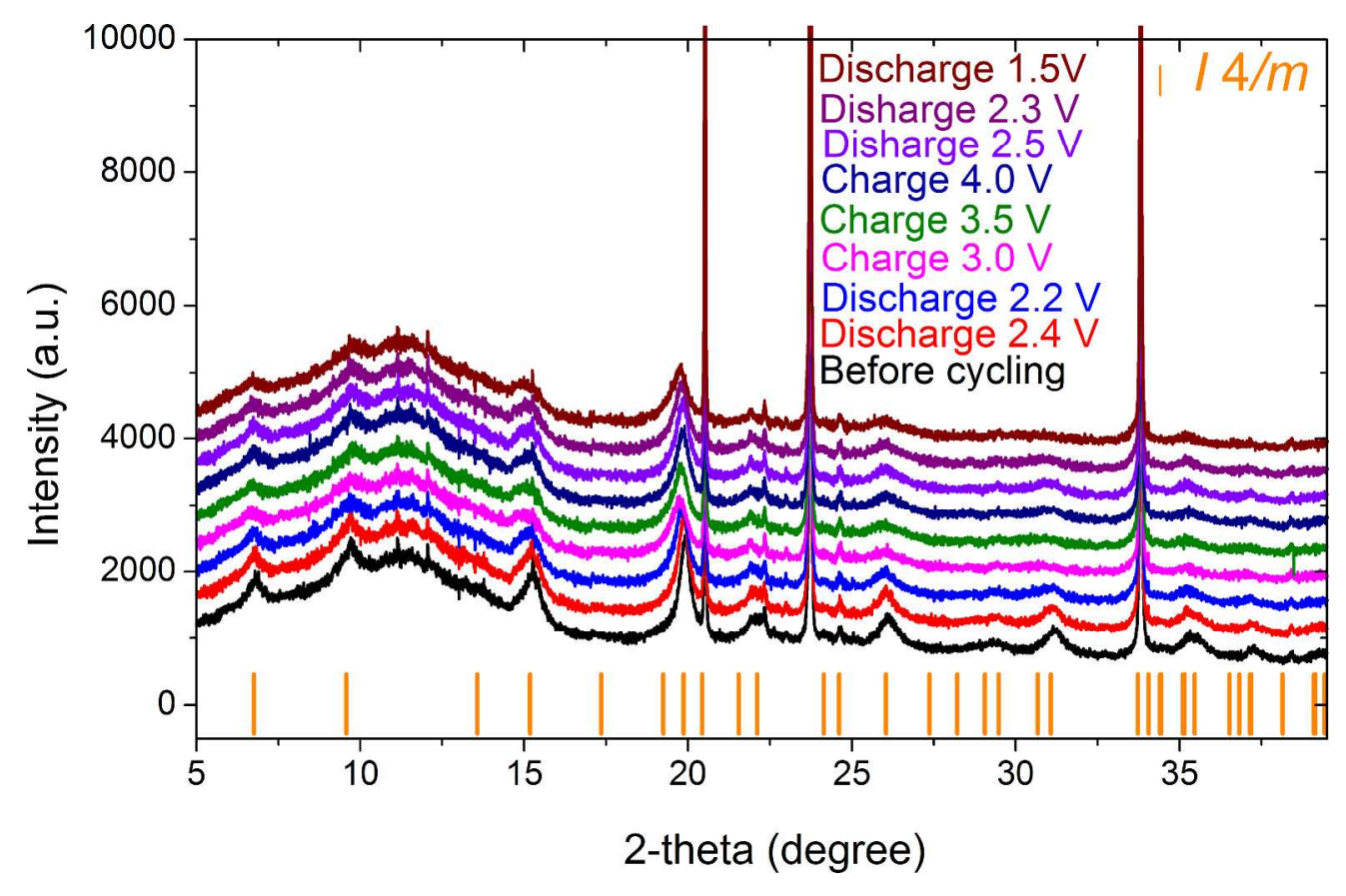

Figure 3

$402 \times 262 \mathrm{~mm}(300 \times 300$ DPI $)$ 


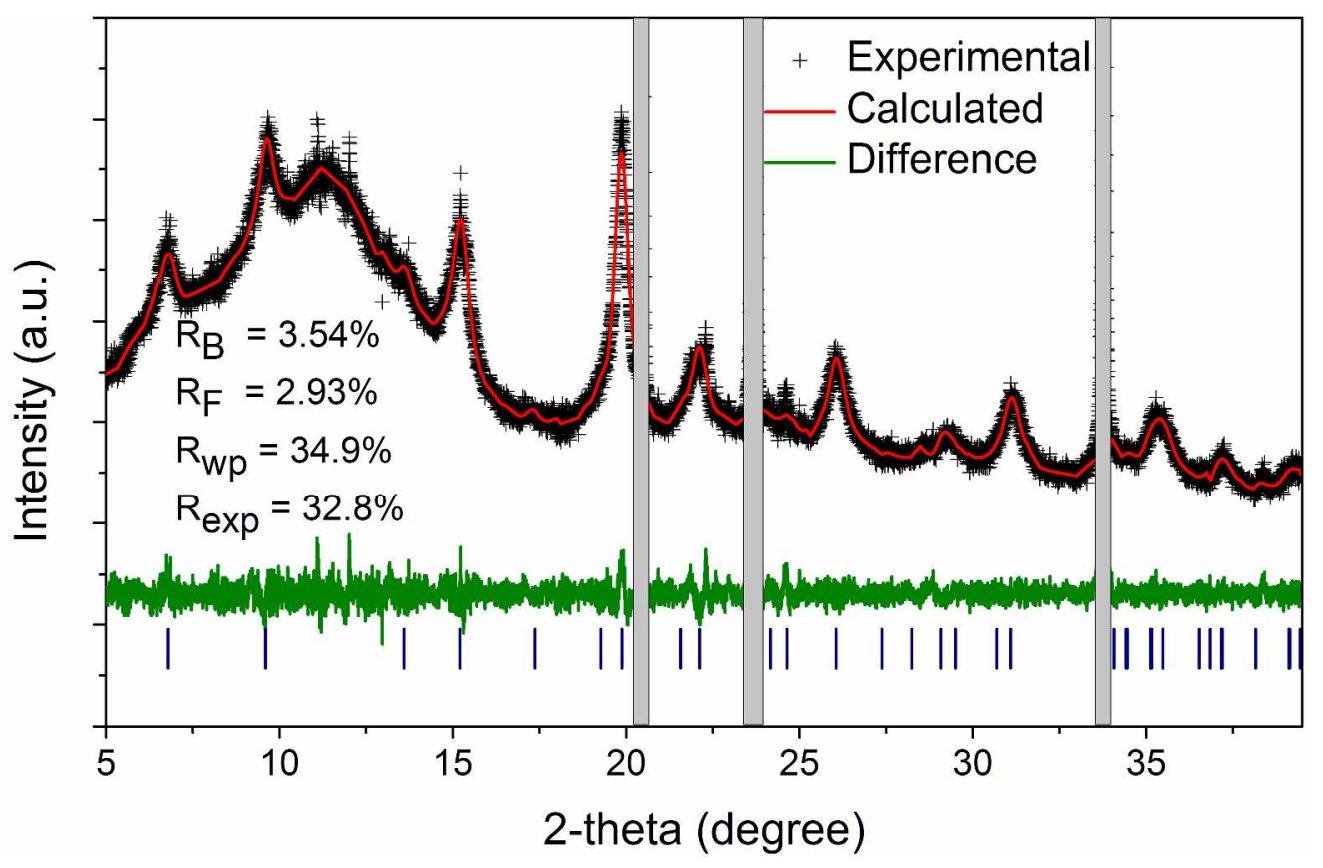

Figure 4

$406 \times 262 \mathrm{~mm}(300 \times 300$ DPI $)$ 


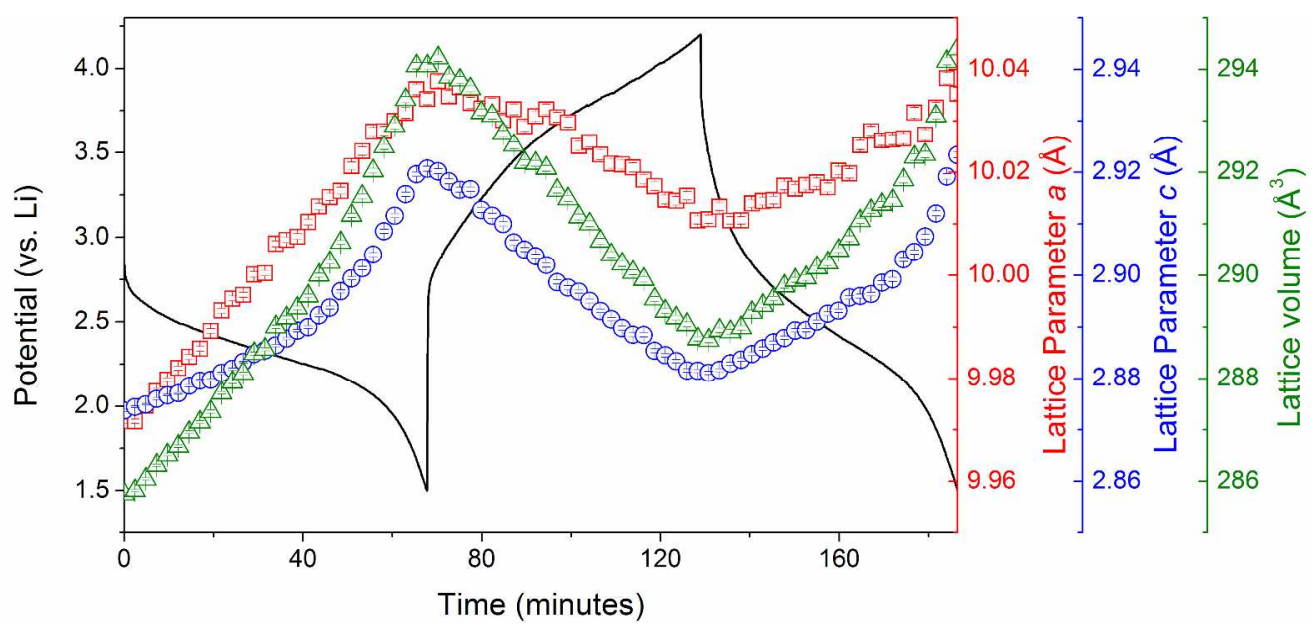

Figure 5 $406 \times 189 \mathrm{~mm}(300 \times 300 \mathrm{DPI})$ 

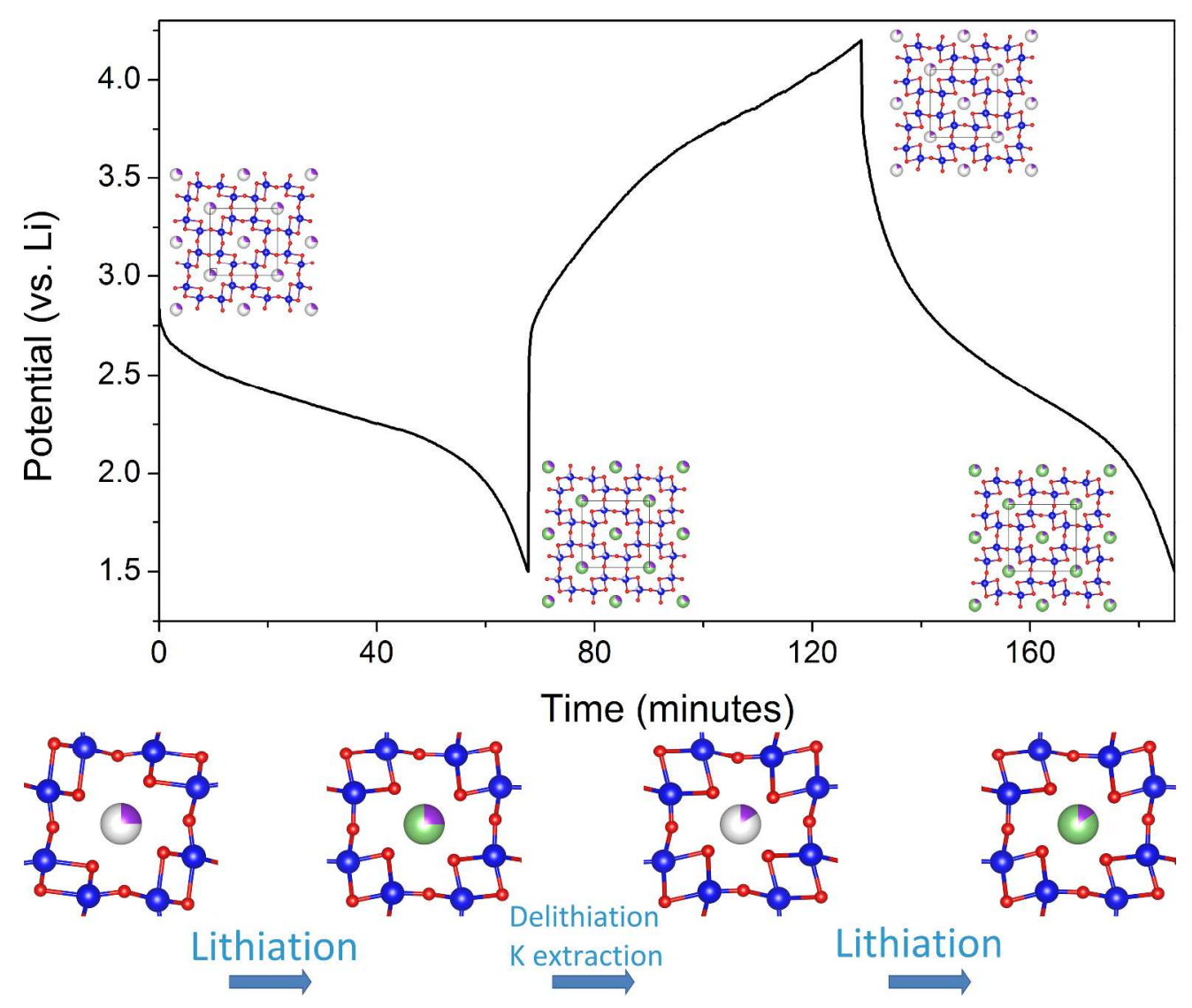

Figure 6

$402 \times 341 \mathrm{~mm}(300 \times 300$ DPI $)$ 
1

2

3

4

5

6

7

8

9

10

11

12

13

14

15

16

17

18

19

20

21

22

23

24

25

26

27

28

29

30

31

32

33

34

35

36

37

38

39

40

41

42

43

44

45

46

47

48

49

50

51

52

53

54

55

56

57

58

59

60

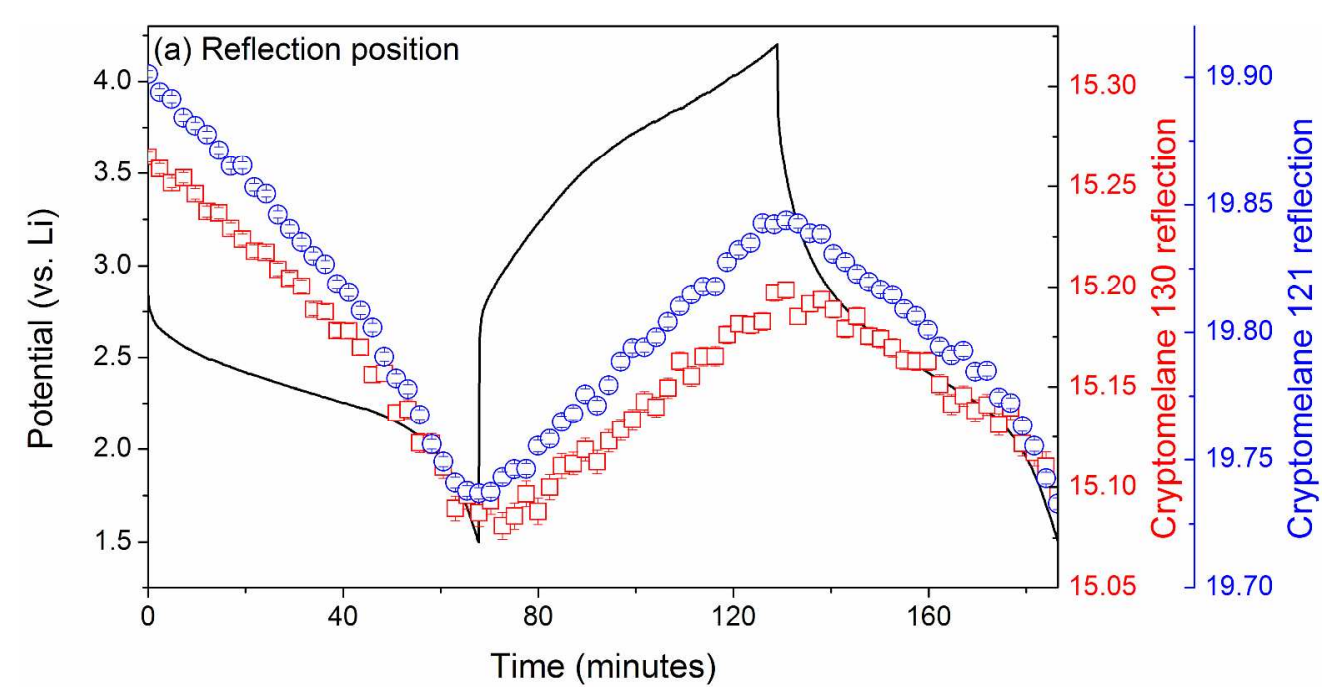

Figure $7 a$

$406 \times 207 \mathrm{~mm}(300 \times 300 \mathrm{DPI})$ 


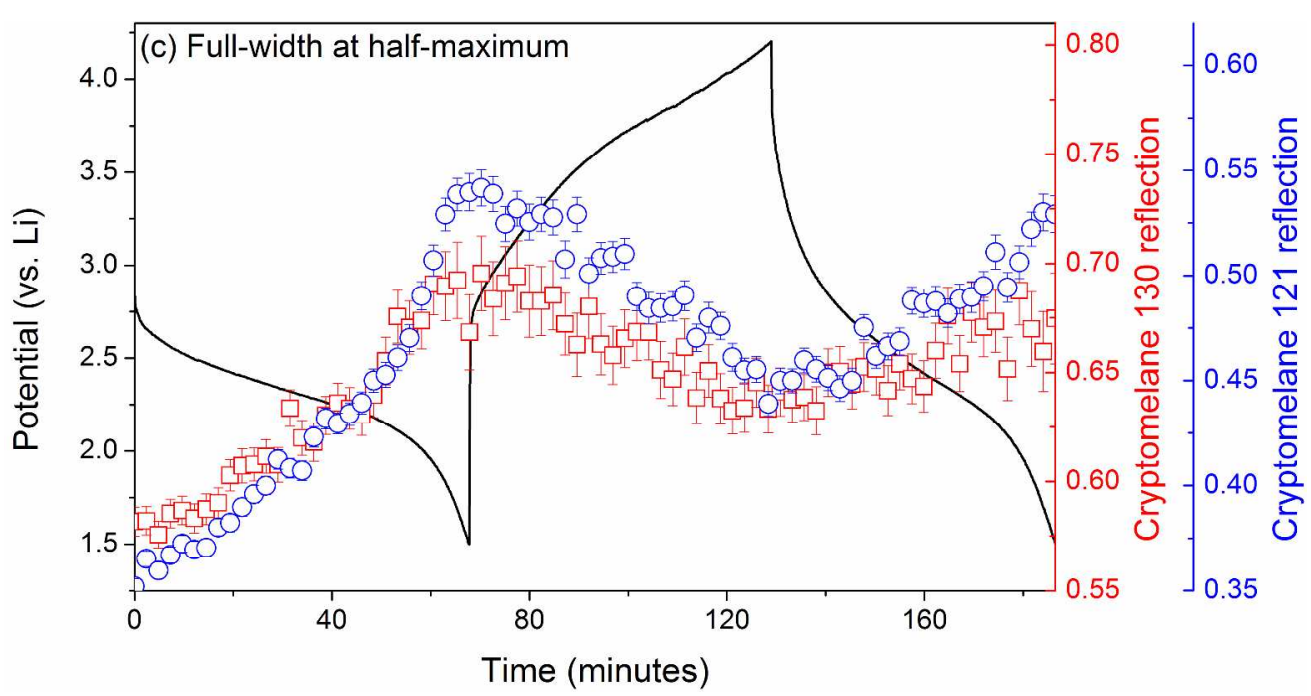

Figure $7 \mathrm{~b}$

$406 \times 209 \mathrm{~mm}(300 \times 300$ DPI $)$ 


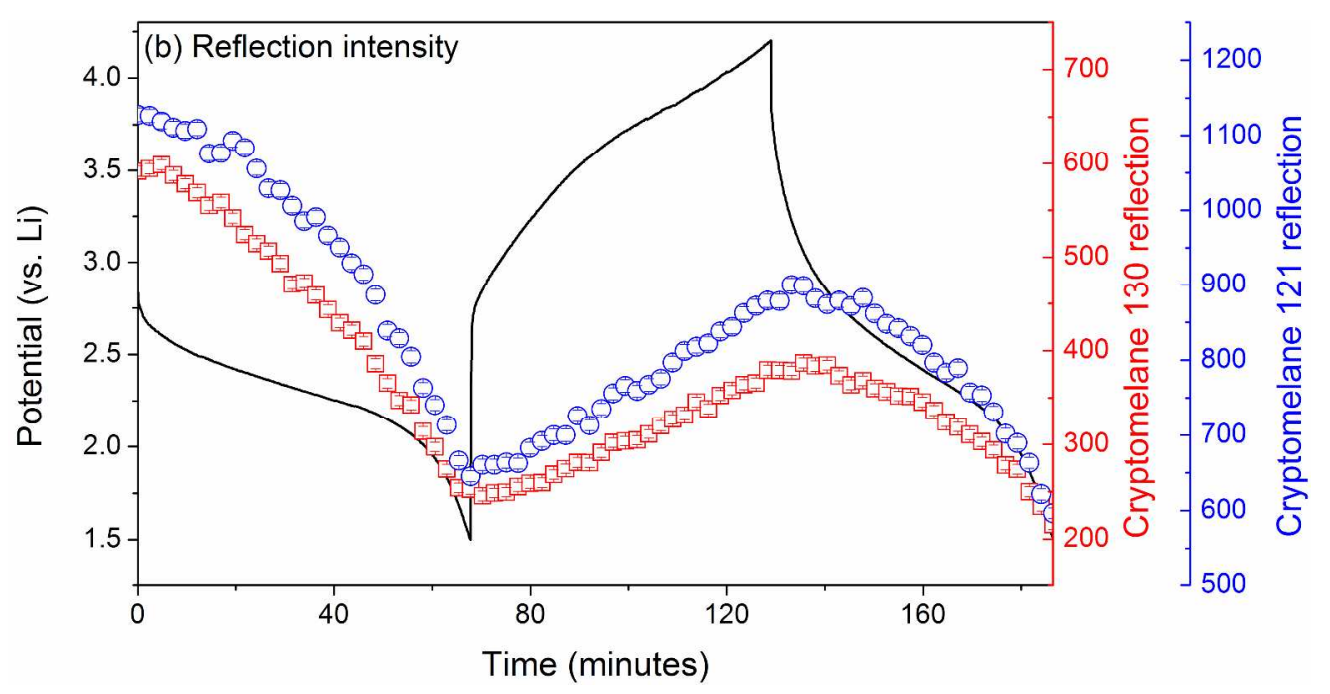

Figure 7c

$406 \times 208 \mathrm{~mm}(300 \times 300$ DPI $)$ 


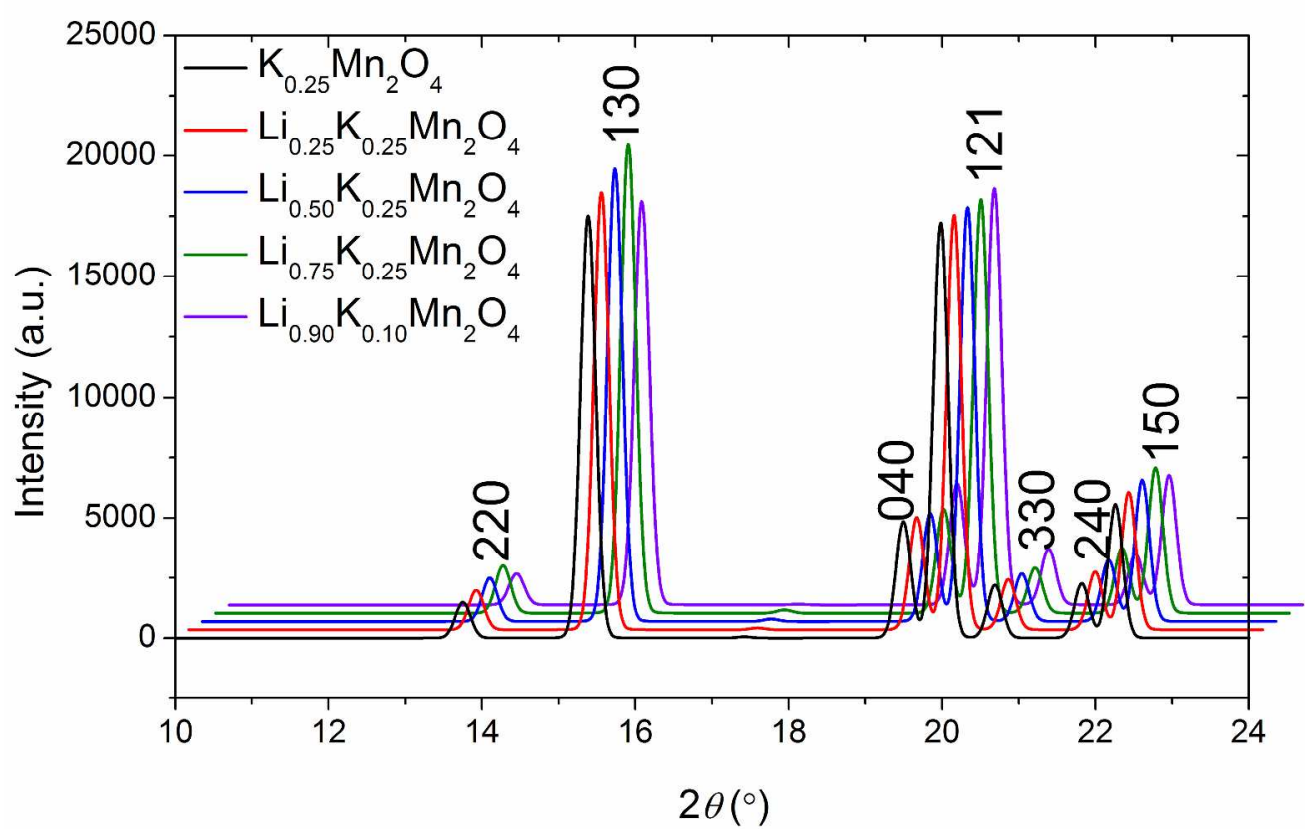

Figure 8

$406 \times 259 \mathrm{~mm}(300 \times 300 \mathrm{DPI})$ 
1

2

3

4

5

6

7

8

9

10

11

12

13

14

15

16

17

18

19

20

21

22

23

24

25

26

27

28

29

30

31

32

33

34

35

36

37

38

39

40

41

42

43

44

45

46

47

48

49

50

51

52

53

54

55

56

57

58

59

60

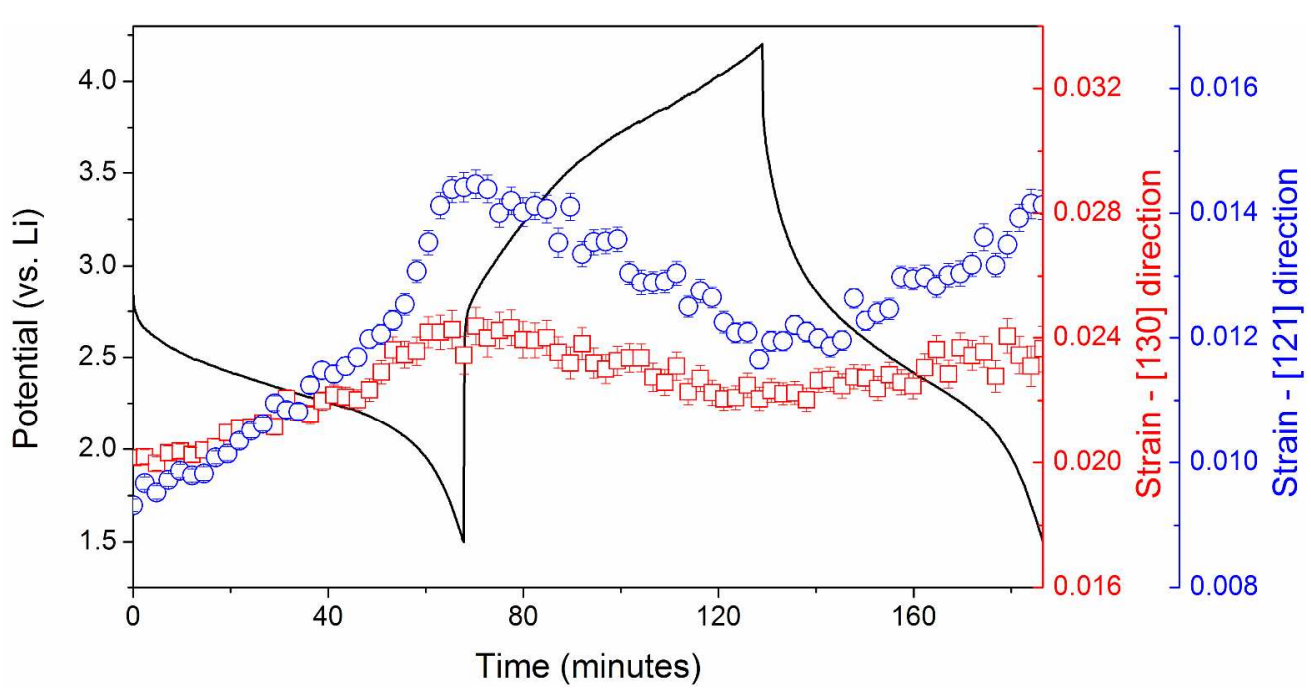

Figure 9

$406 \times 206 \mathrm{~mm}(300 \times 300 \mathrm{DPI})$ 


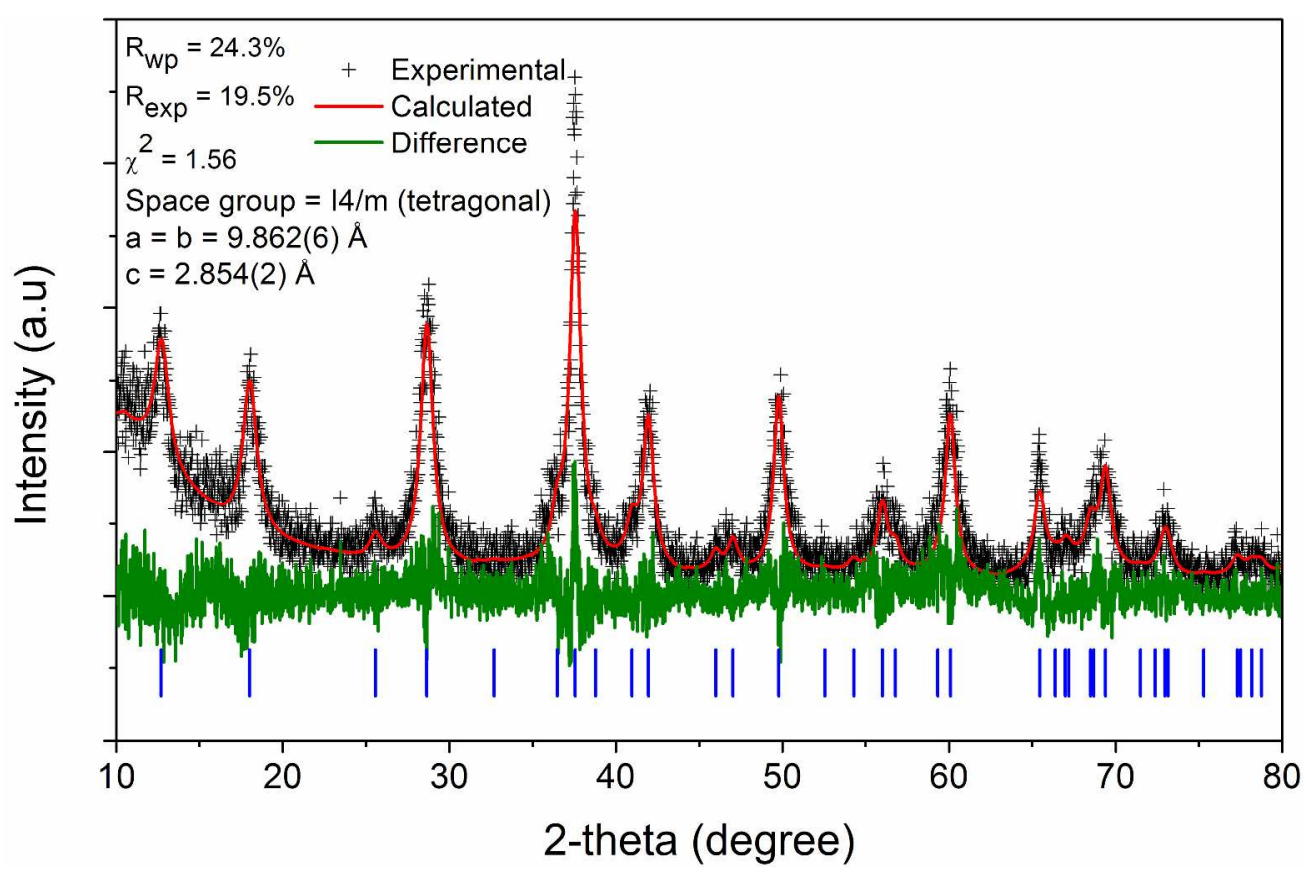

Figure $\mathrm{S} 1$

$406 \times 265 \mathrm{~mm}(300 \times 300$ DPI $)$ 


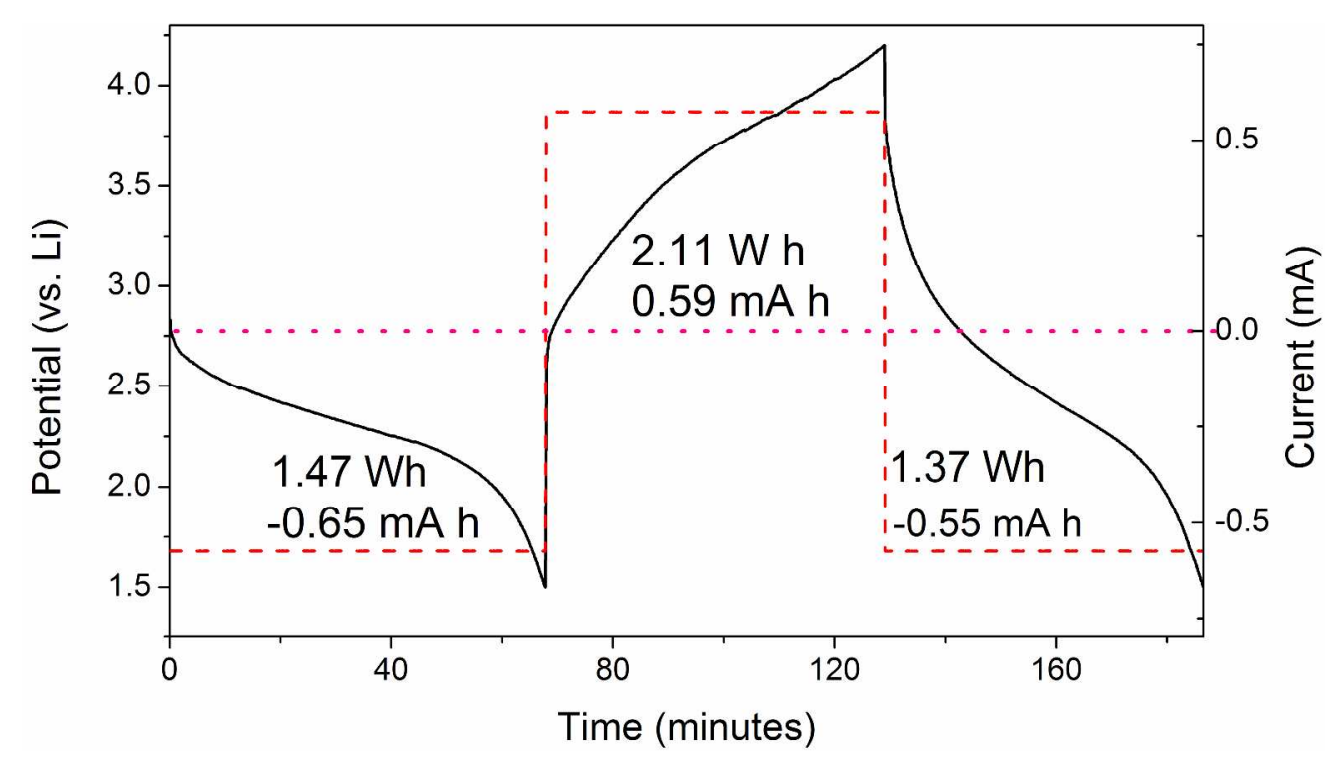

Figure $\mathrm{S} 2$

$406 \times 226 \mathrm{~mm}(300 \times 300$ DPI $)$ 


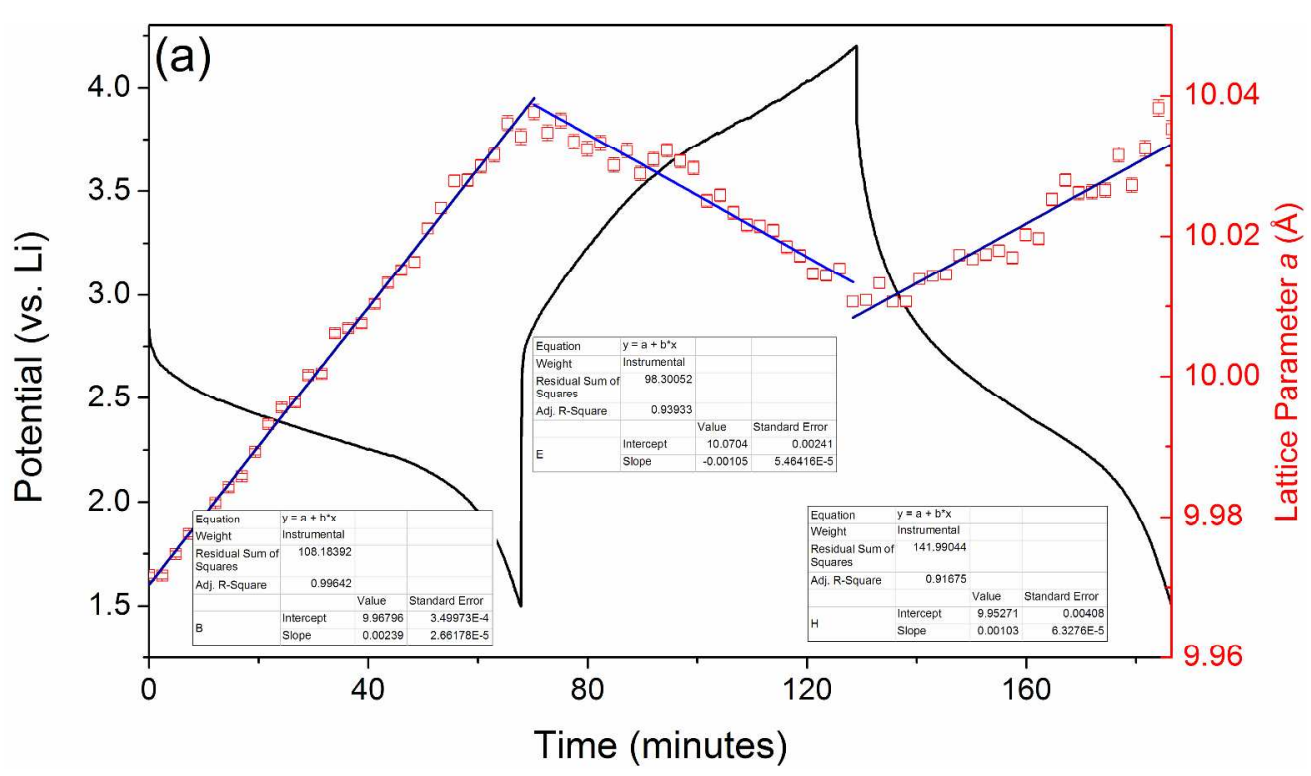

Figure S3a

$406 \times 232 \mathrm{~mm}$ (300 x 300 DPI) 


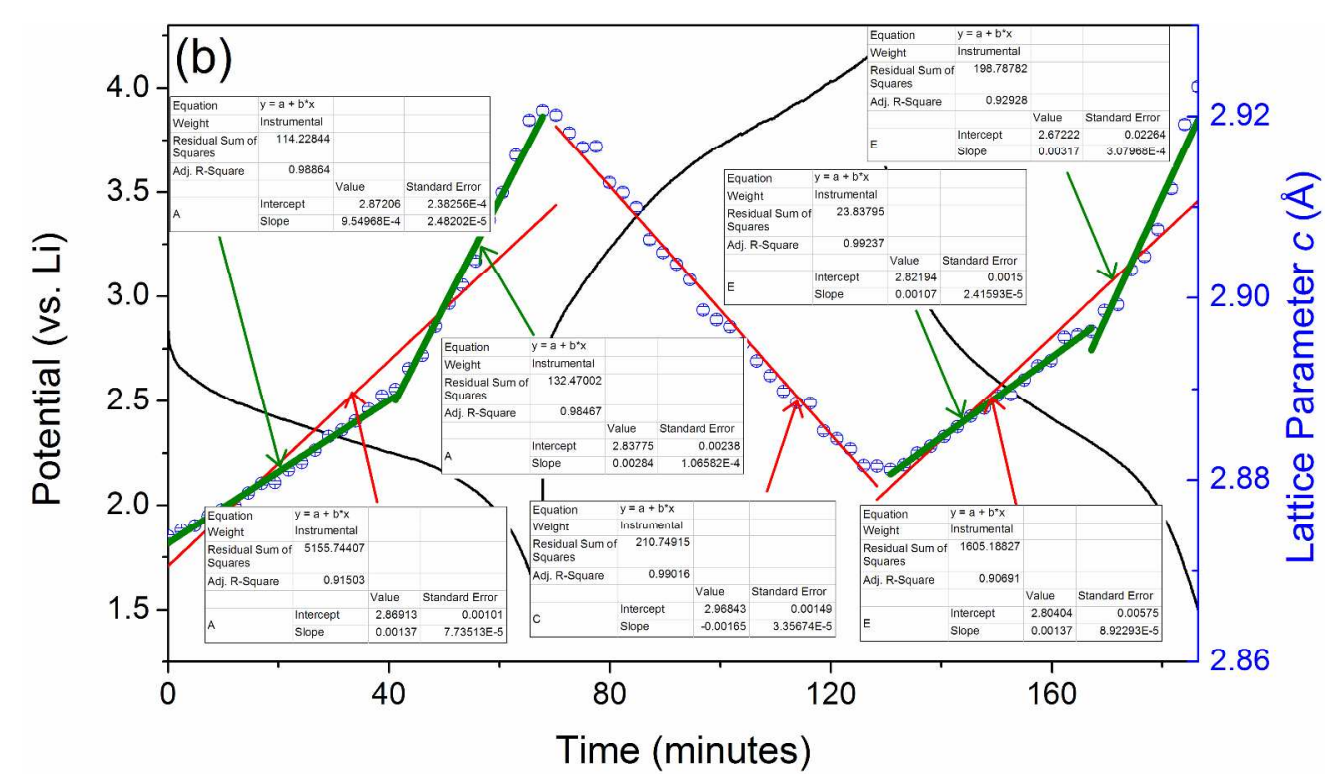

Figure $\mathrm{S} 3 \mathrm{~b}$

$406 \times 234 \mathrm{~mm}$ ( $300 \times 300$ DPI) 


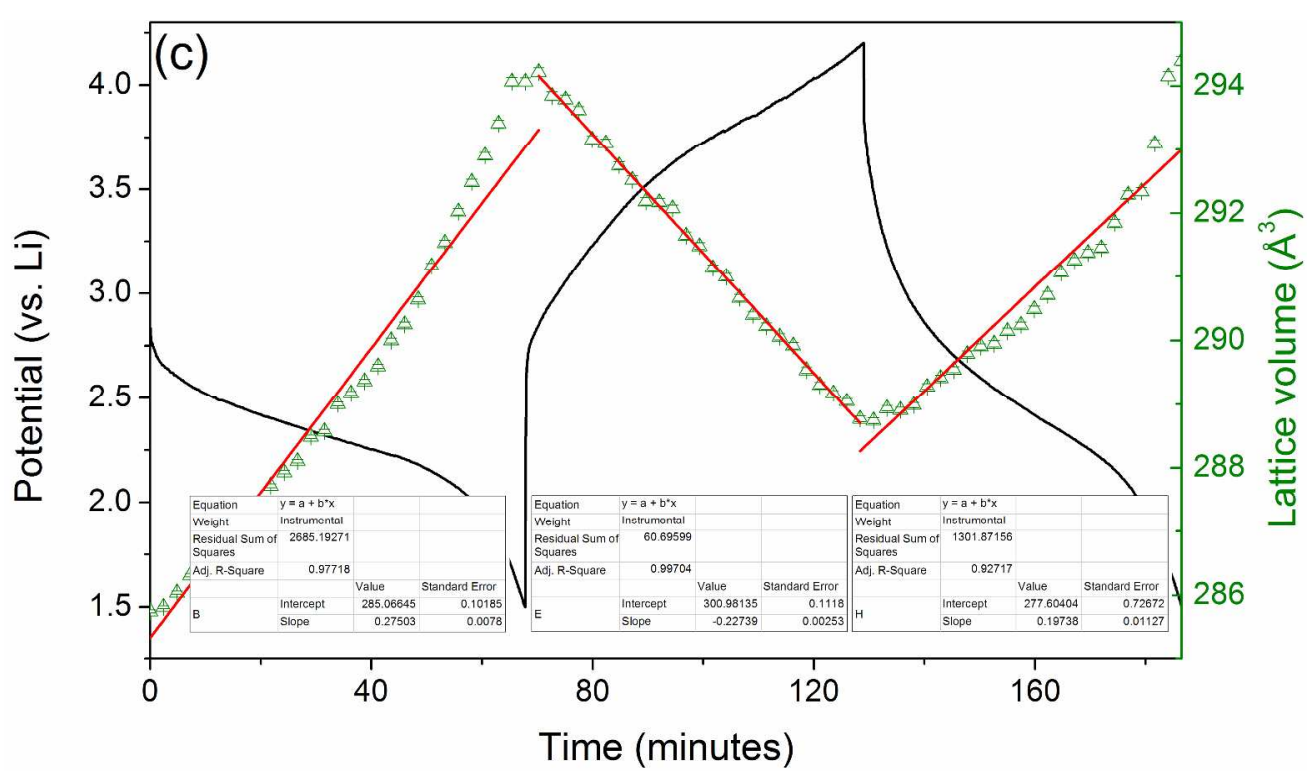

Figure $\mathrm{S} 3 \mathrm{C}$

$406 \times 234 \mathrm{~mm}$ ( $300 \times 300$ DPI) 

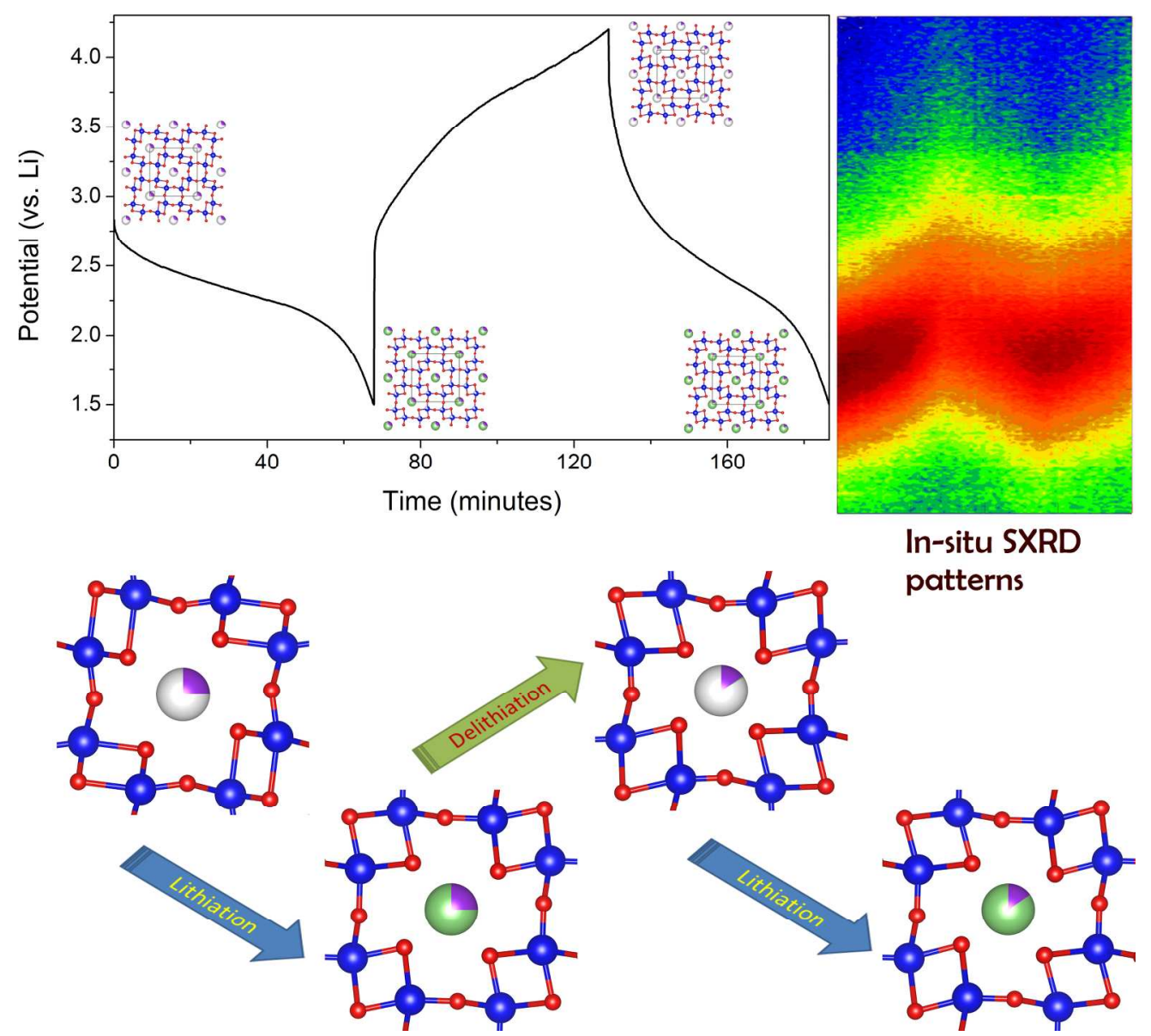

Table of contents $199 \times 181 \mathrm{~mm}(300 \times 300$ DPI $)$ 